\title{
New Views on Inequality Trends in Canada and the United States
}

By

\author{
Michael C. Wolfson* and Brian B. Murphy** \\ 11F0019MPE No. 124 \\ ISSN:1200-5223 \\ ISBN:
}

\author{
Price: $\$ 5.00$ per issue, $\$ 25.00$ annually \\ 24, R.H. Coats Building, Ottawa, K1A 0T6 \\ *Statistics Canada (613) 951-8216 \\ **Statistics Canada (613) 951-3769 \\ Facsimile Number: (613) 951-5643
}

July, 1998

This paper represents the views of the author(s) and does not necessarily reflect the opinions of Statistics Canada. 


\title{
Introduction
}

\author{
Analysis reveals that, from 1974 to 1995, a large portion of Canadian families had absolutely \\ higher purchasing power than their U.S. counterparts; in both countries, individual earnings \\ polarization fell over the past decade.
}

\begin{abstract}
Ce qui est simple est toujours faux, ce qui ne l'est pas est inutilisable. [Whatever is simple is always wrong, whatever is not is unusable]
\end{abstract}

- Paul Valéry

Conventional wisdom has it that U.S. society is both richer and more unequal than Canadian society and that the two have become more unequal in recent decades. Moreover, increasing globalization has raised concerns about a "race to the bottom" - that global competition in the production of traded goods and services is forcing countries with more generous social transfers or more egalitarian wage structures to abandon these mechanisms or risk losing out. This article addresses such conventional wisdom by focusing on a comparison of income inequality in Canada and the United States over the past two decades. Given the similarity of the two countries' societies, as well as their close and growing economic integration, with the highest level of bilateral trade of any two countries in the world, this comparison provides an opportunity to assess the possible impact of globalization on the convergence of income inequality.

The distribution of income in any society is complex and multifaceted. The analysis that follows endeavours to give an overall picture by presenting data from several perspectives. In particular, it starts with data on the labor market from an individual viewpoint and then moves to the broader perspective of families and heir disposable incomes.

A number of intriguing results emerge from the analysis. One is that, even though the U.S. economy appears better off in terms of total output per capita, families (including unattached individuals) living in the United States are not necessarily better off, in terms of disposable income, than their Canadian counterparts. Indeed, roughly half of Canadian families had disposable incomes in 1995 that gave them higher purchasing power than otherwise comparable U.S. families. The reason is that the very rich in the United States pull up the average income much more than in Canada, while those at the bottom of the U.S. income spectrum have less purchasing power than those at the bottom in Canada.

One major factor in these comparisons is the labor market. On average, U.S. workers make more money than their Canadian counterparts; however, the numbers of individuals working for pay in the two countries do not accord with the usual impressions given by comparing official unemployment rates. Also, while trends in the distribution of labor income were quite different in the United States and Canada in the decade from the mid-1970s to the mid-1980s, the following decade, up to 1995, saw much more similar patterns of change in the two countries. 
In terms of labor market inequality, the results of the analysis accord with the conventional wisdom, namely, that inequality has been increasing. However, polarization is an aspect of income distributions (as is the incidence of poverty) that is distinct from inequality, and polarization itself does not always increase when inequality increases. Perhaps surprisingly, this was in fact the case for the U.S. earnings distribution between 1985 and 1995: the proportion of workers with earnings close to the median rose over the period, as it did in Canada. In other words, both countries experienced the opposite of a "disappearing middle class" in their earnings distributions.

What matters more directly to families than individual labor income inequality or polarization is their disposable income - labor income, plus investment returns, plus government transfers, less income taxes and payroll taxes. Family disposable income therefore depends not only on the labor market in each country, but also on national, state, provincial and local government social programs and taxation policies (as well as the correlations among husbands', wives', and other family members' incomes). From this perspective, Canada is clearly "kinder and gentler": both inequality and polarization are considerably lower, and incomes at the bottom of the spectrum are higher than in the United States. Moreover, between 1985 and 1995, both inequality and polarization of family disposable income fell in Canada, while both rose in the United States.

One trend that was similar concerned the low-income population, which, defined simply as those families with half the median family income or less, fell in both countries. The U.S. incidence of low income was about 50 percent higher than Canada's, but contrary to trends based on the official (absolute) U.S. poverty line, low income defined in this relative manner fell in the United States from 1985 to 1995. 


\section{Macroeconomic context}

To place the analysis in context, charts 1 and 2 show trends in two sets of widely used indicators for Canada and the United States over the past 25 years. The trends in gross domestic product (GDP) per capita in chart 1 support the conventional wisdom that the U.S. economy both is richer and has been growing at a somewhat faster rate than the Canadian economy. The reason there are two curves for the U.S. trend is to indicate the sensitivity of this comparison to alternative ways of converting U.S. GDP per capita from U.S. dollars into Canadian dollars of equivalent purchasing power. The standard approach is to use purchasing power parities rather than the exchange rate, but there are several such measures available. (See appendix.) In the comparison presented in chart 1, the specific measure chosen does not affect the overall result, but it will be important in subsequent comparisons between the two countries.

Chart 2 shows trends in two sets of official labor market indicators. Employment-topopulation ratios have been trending up slowly in both countries, although the U.S. rate has moved ahead of Canada's since the later 1980s. Unemployment rates, which once were similar in the two countries, began to diverge in the early 1980s, with the Canadian rate now almost double that of the United States. This suggests a weaker labor market in Canada.

\section{Workers and labor market earnings}

Given the foregoing background, this section focuses on individual incomes from working. The next section considers family disposable income. ${ }^{1}$

Average earnings. The major source of income for the vast majority of families is from working. Income is defined in this article to include both employment and self-employment income, or "earnings," for short. Table 1 shows earnings for the United States and Canada over the past two decades. ${ }^{2}$ Both mean and median earnings are presented for all "working-age" individuals, defined as those aged 18 to 64, and also separately for men and women. In this table, dollar amounts are "own-country" currencies.

These earnings data support the view that the U.S. economy has been growing faster overall than Canada's. From the information in the first row, mean earnings in Canada grew by (Canadian) $\$ 600$ over the first decade and then by $\$ 900$ over the second decade, while in the United States, it grew by (U.S.) $\$ 1,300$ and then by $\$ 2,400 .^{3}$ However, median earnings, shown in the second row, fell in Canada from 1974 to 1985 and then rose by more than $\$ 1,000$, while in the United States, median earnings grew by about $\$ 1,400$ and then $\$ 800$ during the respective periods.

These mean- and median-earnings figures reveal somewhat different trends than does GDP per capita, shown in chart 1, which grew in both countries more from 1974 to 1985 than from 1985 to 1995. Part of the reason for this difference as to which decade saw faster growth is that the population of earners has also been changing. (Yet another perspective on these rates of income growth is given for family disposable income in the section of the same name.)

The third row of table 1 shows the proportion of individuals aged 18 to 64 who reported at last $\$ 500$ (in 1995 Canadian dollars) in earnings for the year. This threshold has been used to define "effective labour force participant," the satisfaction of which is the basic criterion for someone's being an "earner" in this analysis. The concept differs from the official employment- 
to-population ratio, which is simply the average of the 12 monthly ratios over a calendar year. Instead, status as an effective labor force participant is based on nontrivial annual labor force attachment, defined in terms of receiving a minimal amount of income from work over the calendar year. ${ }^{4}$

The proportion of the working-age population who were effective labor force participants grew a bit faster in the United States than in Canada. Interestingly, however, both countries had essentially the same proportion of working-age effective labor force participants in 1995, notwithstanding the fact that Canada's unemployment rate was almost double that of the United States that year and that the U.S. employment-to-population ratio was several percentage points higher than Canada's, as shown in chart $2 .^{5}$ 
Chart 1. Real domestic product per capital, Canada and United States (using two measures of purchasing power parity), 1970-1995

Thousands of Canadian dollars

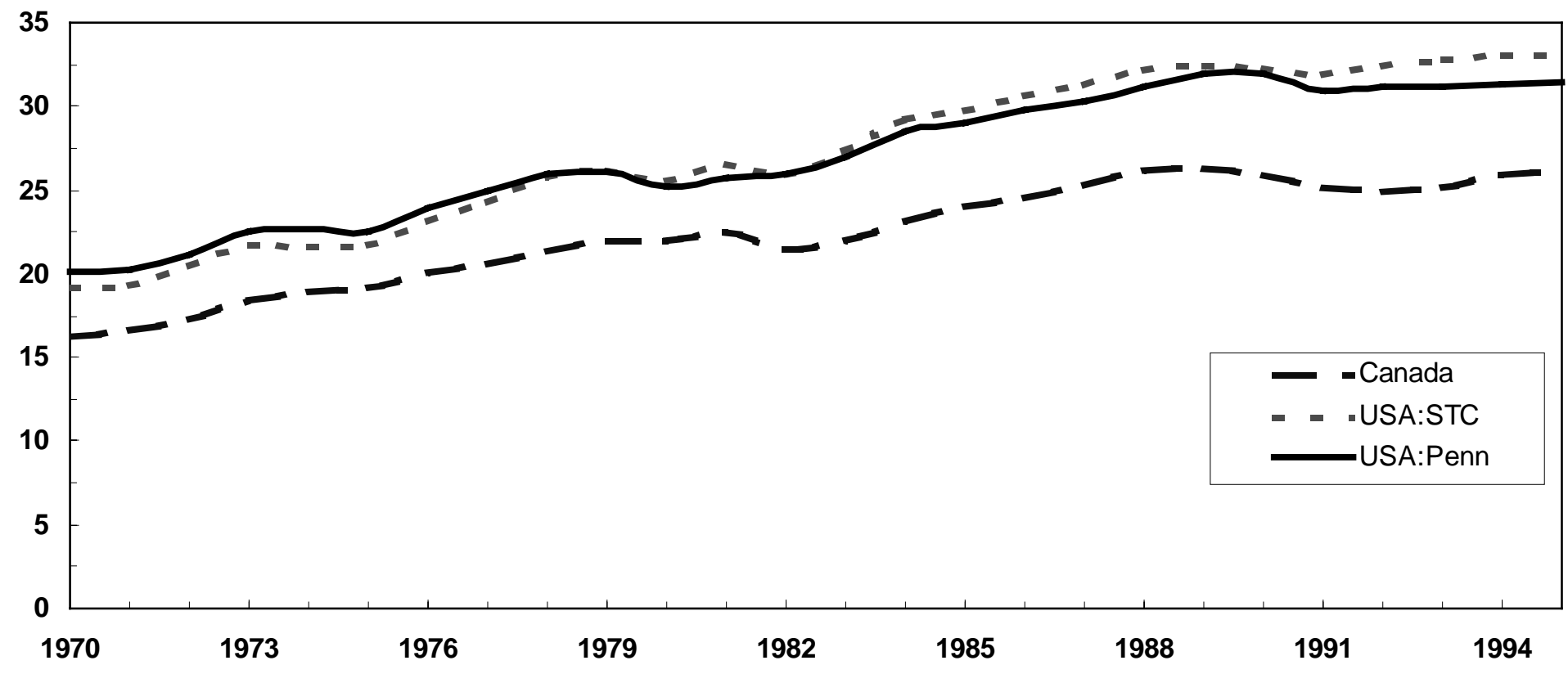

Chart 2. Employment-to-population ratio and unemployment rate, Canada and Percent United States, workers aged 15 and older, 1970-1995

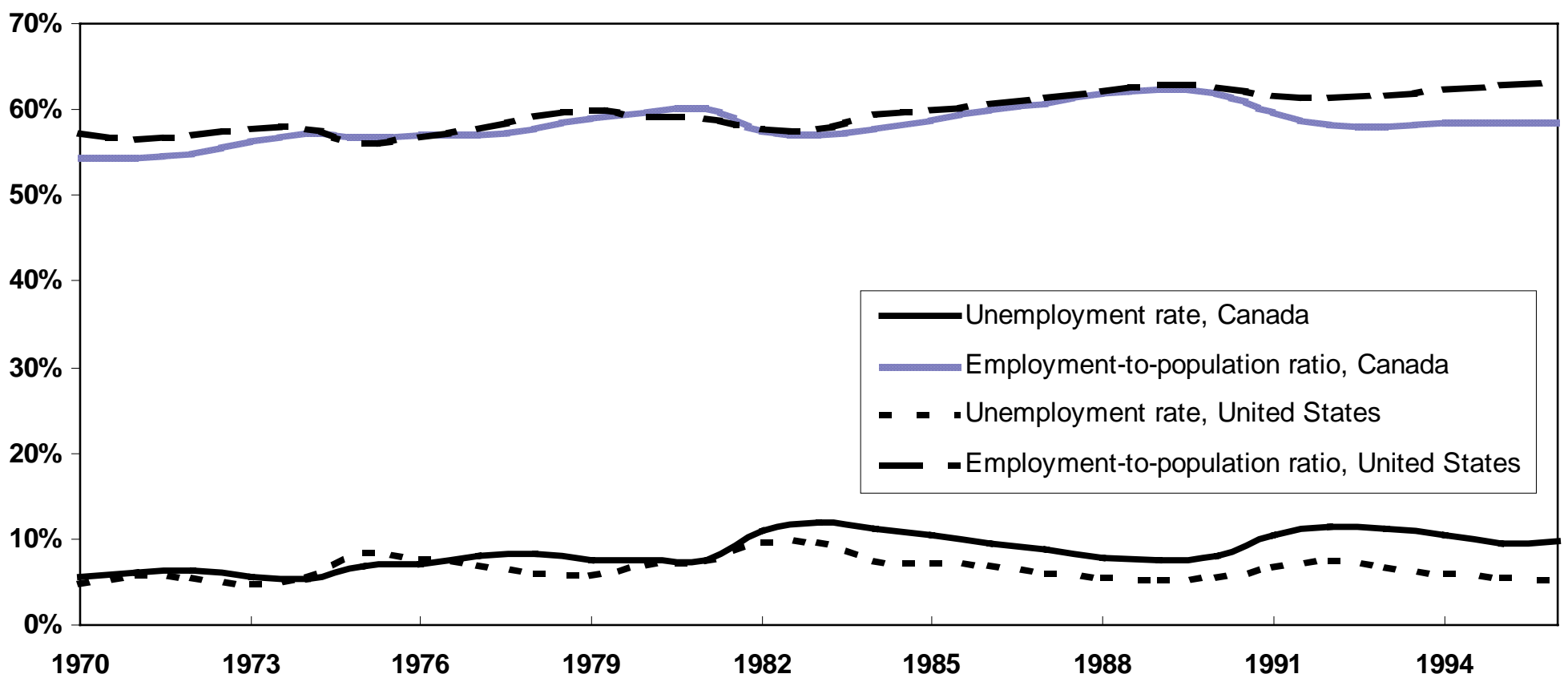


The data in table 1 do not allow direct comparisons of earnings levels between Canada and the United States, because dollar amounts are all expressed in own-country currencies. Hence table 2 shows mean and median income for all effective labor force participants aged 18 to 64, this time in Canadian dollars. Two conversion rates have been used in order to give an indication of the sensitivity of the results to the specific choice of measure of purchasing power parity. (See appendix.)

The one year in which real Canadian mean and median earnings were higher than in the United States was in 1974. In 1995, Canadian median earnings were anywhere from $\$ 250$ to $\$ 2,250$ lower than the corresponding U.S. figure, depending on the measure of purchasing power parity used, while mean earnings were from $\$ 2,500$ to $\$ 5,500$ lower - about $\$ 16,500$ in Canada, compared with $\$ 16,800$ to $\$ 18,800$ (in Canadian dollars) for the United States.

Earnings inequality and polarization. To explore trends in individual earnings inequality, table 3 presents a series of statistics for four groupings of effective labor force participants (that is, those with annual earnings of at least $\$ 500$, in 1995 Canadian dollars): first working-age (18 to 64 years) men, then working-age women, then both combined, and finally, all effective labor force participants aged 15 or older. The first five rows of data show quintile earnings shares. The next two rows then break the top quintile in half, showing the shares of the $9^{\text {th }}$ and 10th deciles, while the following row gives the Gini coefficient. All of these measures are standard indicators of income inequality.

Another way to characterize income distributions is in terms of polarization. This notion was motivated by the 1980s debate on the "disappearing middle class. " While the distinction is not widely appreciated, polarization and inequality are different concepts. For example, income distributions can change in ways such that polarization goes up while inequality goes down, or vice versa. (See appendix.)

Accordingly, the remaining rows for each of the four population groups in table 3 show polarization indicators. One such indicator gives the proportions of the population with earnings in various ranges straddling the median level of earnings. For example, the row labeled "75150 "gives the proportion of earners with earnings between 75 percent and 150 percent of the median, one possible definition of the middle class. If this proportion falls, we can usually conclude that the proportion of middle-range earners is falling, so that the distribution is becoming more spread out from the middle, or more polarized. The last row shows figures for a summary measure of polarization that is analogous to the Gini coefficient. (See appendix.)

None of these indicators provides a complete measure of trends in inequality or polarization. Rather, the widely accepted "gold standard" for inequality comparisons is the underlying Lorenz curves, and there are analogous polarization curves. In comparisons of two income distributions, however, either of these kinds of curves can cross (and not necessarily in the same way), in which case an unambiguous ranking of inequality or polarization is impossible. Thus, even though no graphs of the underlying Lorenz or polarization curves are presented, the conclusions have in all cases been based on inspection of these underlying curves. 


\begin{tabular}{|c|c|c|c|c|c|c|}
\hline \multirow{4}{*}{\begin{tabular}{ll}
\multicolumn{2}{c}{ Category } \\
Total.
\end{tabular}} & orker & $\begin{array}{l}\text { d } 181 \\
\text { ion, }\end{array}$ & $\begin{array}{l}\text { years, } \\
\text { la and }\end{array}$ & in-col & $\begin{array}{ll}\text { lous } \\
74,1\end{array}$ & $\begin{array}{l}1995 \\
\text { d } 1995\end{array}$ \\
\hline & \multicolumn{3}{|c|}{ Canada } & \multicolumn{3}{|c|}{ United States } \\
\hline & 1974 & 1985 & 1995 & 1974 & 1985 & 1995 \\
\hline & & & & & & \\
\hline \multirow{3}{*}{ 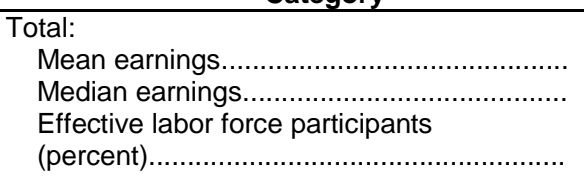 } & 20.4 & 21.1 & 21.9 & 18.2 & 19.6 & 21.9 \\
\hline & 15.8 & 15.5 & 16.5 & 12.7 & 14.2 & 15.0 \\
\hline & 74.2 & 78.9 & 79.3 & 73.9 & 77.1 & 79.3 \\
\hline \multicolumn{7}{|l|}{ Men: } \\
\hline 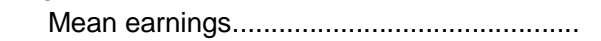 & 32.0 & 29.4 & 28.3 & 28.8 & 27.9 & 29.3 \\
\hline 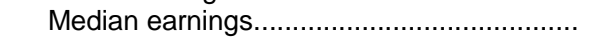 & 30.1 & 26.4 & 24.3 & 26.4 & 22.7 & 22.0 \\
\hline 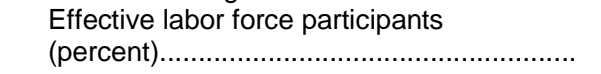 & 93.6 & 89.7 & 86.1 & 89.9 & 87.0 & 86.2 \\
\hline \multicolumn{7}{|l|}{ Women: } \\
\hline 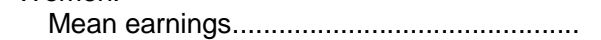 & 8.9 & 12.7 & 15.6 & 8.3 & 11.6 & 14.8 \\
\hline 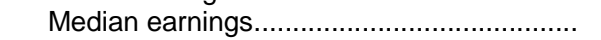 & 2.3 & 7.2 & 10.2 & 2.9 & 7.1 & 10.0 \\
\hline $\begin{array}{l}\text { Effective labor force participants } \\
\text { (percent) }\end{array}$ & 54.9 & 68.1 & 72.5 & 58.8 & 68.6 & 72.7 \\
\hline \multicolumn{7}{|l|}{ Table 2.} \\
\hline \multirow[b]{2}{*}{ Category } & \multicolumn{3}{|c|}{ Canada } & \multicolumn{3}{|c|}{ United States } \\
\hline & 1974 & 1985 & 1995 & 1974 & 1985 & 1995 \\
\hline \multirow{4}{*}{ 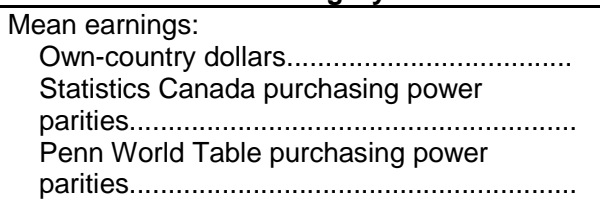 } & & & & & & \\
\hline & 20.4 & 21.1 & 21.9 & 18.2 & 19.6 & 21.9 \\
\hline & 20.4 & 21.1 & 21.9 & 20.1 & 25.2 & 27.4 \\
\hline & 20.4 & 21.1 & 21.9 & 18.9 & 22.0 & 24.5 \\
\hline \multirow{4}{*}{ 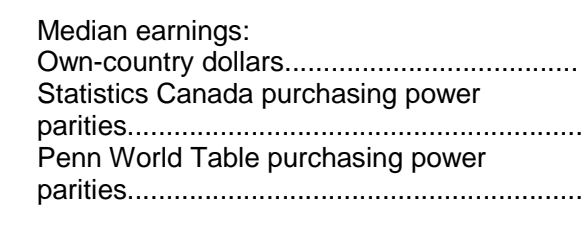 } & & & & & & \\
\hline & 15.8 & 15.5 & 16.5 & 12.7 & 14.2 & 15.0 \\
\hline & 15.8 & 15.5 & 16.5 & 14.0 & 18.3 & 18.8 \\
\hline & 15.8 & 15.5 & 16.5 & 13.2 & 15.9 & 16.8 \\
\hline
\end{tabular}




\section{Table 3.}

Earnings inequality and polarization indicators for effective labor force participants, 1974, 1985 and 1995

\begin{tabular}{|c|c|c|c|c|c|c|}
\hline \multirow[b]{2}{*}{ Quintile or decile and indicator } & \multicolumn{3}{|c|}{ Canada } & \multicolumn{3}{|c|}{ United States } \\
\hline & 1974 & 1985 & 1995 & 1974 & 1985 & 1995 \\
\hline \multicolumn{7}{|l|}{ Men, $18-64$ years } \\
\hline \multicolumn{7}{|l|}{ Indicators of inequality: } \\
\hline 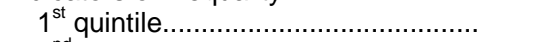 & 4.8 & 3.4 & 3.5 & 4.2 & 3.5 & 3.4 \\
\hline 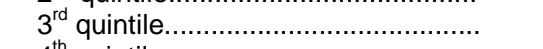 & 18.4 & 18.1 & 17.6 & 17.9 & 16.9 & 15.3 \\
\hline 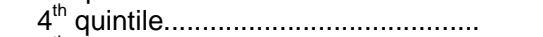 & 24.0 & 25.8 & 25.2 & 24.2 & 24.5 & 22.5 \\
\hline 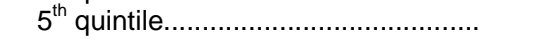 & 40.2 & 42.0 & 43.2 & 41.9 & 44.7 & 49.2 \\
\hline $9^{\text {th }}$ decile $. . . . \ldots \ldots \ldots \ldots \ldots \ldots \ldots . . . . .$. & 15.2 & 16.6 & 16.6 & 15.7 & 16.4 & 15.7 \\
\hline 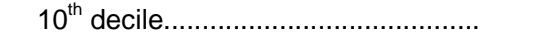 & 25.0 & 25.3 & 26.6 & 26.2 & 28.3 & 33.5 \\
\hline Gini coefficient................................... & 0.352 & 0.392 & 0.401 & 0.375 & 0.413 & 0.455 \\
\hline \multicolumn{7}{|l|}{$\begin{array}{l}\text { Indicators of polarization } \\
\text { (percent of median) }\end{array}$} \\
\hline 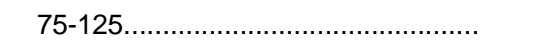 & 33.6 & 23.8 & 25.2 & 31.3 & 23.8 & 24.5 \\
\hline 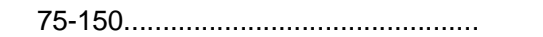 & 46.2 & 35.7 & 35.8 & 44.0 & 34.7 & 34.3 \\
\hline 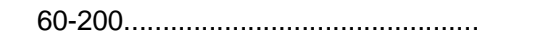 & 67.3 & 58.8 & 57.1 & 65.1 & 57.4 & 55.4 \\
\hline 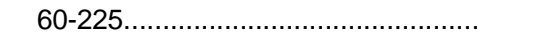 & 70.0 & 63.0 & 61.9 & 67.3 & 61.4 & 59.1 \\
\hline "Polarization coefficient"....................... & 0.278 & 0.363 & 0.363 & 0.302 & 0.376 & 0.396 \\
\hline \multicolumn{7}{|l|}{ Women, 18 to 64 years } \\
\hline \multicolumn{7}{|l|}{ Indicators of inequality: } \\
\hline 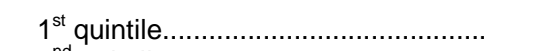 & 3.2 & 2.8 & 3.1 & 2.8 & 2.8 & 3.1 \\
\hline 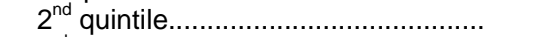 & 9.6 & 9.1 & 9.3 & 9.1 & 9.3 & 9.4 \\
\hline 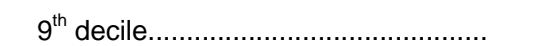 & 17.1 & 17.8 & 17.6 & 18.0 & 17.8 & 17.2 \\
\hline 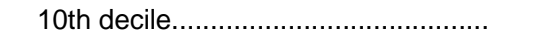 & 26.0 & 26.9 & 26.9 & 26.4 & 27.3 & 29.8 \\
\hline 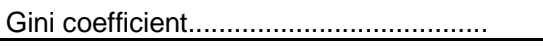 & 0.408 & 0.426 & 0.421 & 0.424 & 0.428 & 0.441 \\
\hline \multicolumn{7}{|l|}{$\begin{array}{l}\text { Indicators of polarization } \\
\text { (percent of median): }\end{array}$} \\
\hline 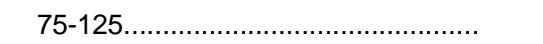 & 22.5 & 20.0 & 20.3 & 20.5 & 21.5 & 22.4 \\
\hline 75-150..................................... & 33.8 & 28.9 & 29.9 & 29.6 & 31.6 & 30.4 \\
\hline 60-200..................................... & 54.7 & 50.4 & 51.5 & 50.4 & 52.3 & 52.7 \\
\hline 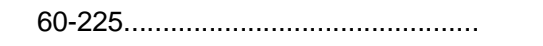 & 58.4 & 54.9 & 56.2 & 55.3 & 55.9 & 56.8 \\
\hline "Polarization coefficient"....................... & 0.389 & 0.436 & 0.425 & 0.436 & 0.429 & 0.424 \\
\hline \multicolumn{7}{|l|}{$\begin{array}{l}\text { All effective labor force participants, } \\
\qquad 18-64 \text { years }\end{array}$} \\
\hline \multicolumn{7}{|l|}{ Indicators of inequality: } \\
\hline 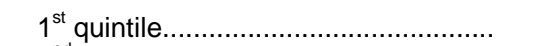 & 3.4 & 2.9 & 3.1 & 2.8 & 2.8 & 3.0 \\
\hline $2^{\text {nd }}$ quintile.................................... & 10.4 & 9.3 & 9.5 & 9.4 & 9.2 & 9.0 \\
\hline $3^{\text {rd }}$ quintile....................................... & 17.4 & 16.9 & 17.0 & 16.6 & 16.0 & 15.2 \\
\hline 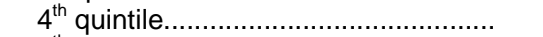 & 25.0 & 25.9 & 25.4 & 25.1 & 24.7 & 23.0 \\
\hline 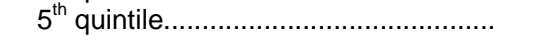 & 43.8 & 45.1 & 45.0 & 46.1 & 47.4 & 49.8 \\
\hline 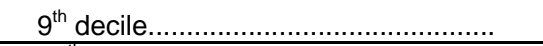 & 16.5 & 17.8 & 17.3 & 17.2 & 17.4 & 16.4 \\
\hline 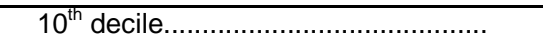 & 27.3 & 27.3 & 27.7 & 28.9 & 30.0 & 33.4 \\
\hline
\end{tabular}




\begin{tabular}{|c|c|c|c|c|c|c|}
\hline \multirow[b]{2}{*}{$\begin{array}{l}\text { Quintile or decile and indicator } \\
\text { Gini coefficient...................................... }\end{array}$} & \multicolumn{3}{|c|}{ Canada } & \multicolumn{3}{|c|}{ United States } \\
\hline & $\begin{array}{l}1974 \\
0.407\end{array}$ & $\begin{array}{l}1985 \\
0.428\end{array}$ & $\begin{array}{l}1995 \\
0.423\end{array}$ & $\begin{array}{l}1974 \\
0.436\end{array}$ & $\begin{array}{l}1985 \\
0.447\end{array}$ & $\begin{array}{l}1995 \\
0.467\end{array}$ \\
\hline \multicolumn{7}{|l|}{$\begin{array}{l}\text { Indicators of polarization } \\
\text { (percent of median): }\end{array}$} \\
\hline 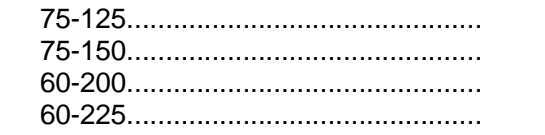 & $\begin{array}{l}24.1 \\
35.4 \\
57.3 \\
61.5\end{array}$ & $\begin{array}{l}21.6 \\
29.7 \\
50.8 \\
55.6\end{array}$ & $\begin{array}{l}21.7 \\
32.0 \\
52.5 \\
57.2\end{array}$ & $\begin{array}{l}21.2 \\
31.4 \\
52.4 \\
56.5\end{array}$ & $\begin{array}{l}21.2 \\
30.7 \\
50.6 \\
55.0\end{array}$ & $\begin{array}{l}22.9 \\
31.6 \\
52.0 \\
56.0\end{array}$ \\
\hline $\begin{array}{l}\text { "Polarization coefficient".......................... } \\
\text { All effective labor force participants, } 15 \\
\text { and older }\end{array}$ & 0.374 & 0.427 & 0.407 & 0.414 & 0.433 & 0.425 \\
\hline \multicolumn{7}{|l|}{ Indicators of inequality: } \\
\hline 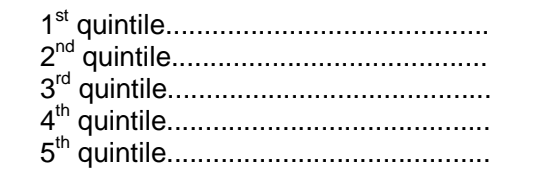 & $\begin{array}{c}2.7 \\
9.5 \\
17.1 \\
25.4 \\
45.3\end{array}$ & $\begin{array}{c}2.4 \\
8.6 \\
16.7 \\
26.1 \\
46.2\end{array}$ & $\begin{array}{c}2.7 \\
9.0 \\
16.8 \\
25.6 \\
45.8\end{array}$ & $\begin{array}{c}2.2 \\
8.3 \\
16.2 \\
25.5 \\
47.9\end{array}$ & $\begin{array}{c}2.3 \\
8.5 \\
15.7 \\
24.9 \\
48.5\end{array}$ & $\begin{array}{c}2.6 \\
8.5 \\
15.0 \\
23.1 \\
50.8\end{array}$ \\
\hline 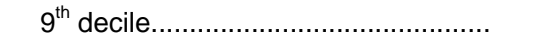 & 17.0 & 18.1 & 17.6 & 17.7 & 17.7 & 16.7 \\
\hline $10^{\text {th }}$ decile........... & 28.3 & 28.0 & 28.2 & 30.1 & 30.8 & 34.1 \\
\hline Gini coefficient....................................... & 0.431 & 0.444 & 0.436 & 0.463 & 0.465 & 0.481 \\
\hline \multicolumn{7}{|l|}{$\begin{array}{l}\text { Indicators of polarization } \\
\text { (percent of median): }\end{array}$} \\
\hline 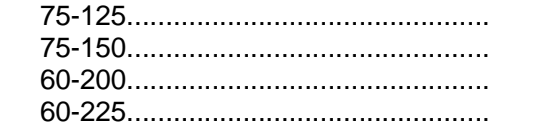 & $\begin{array}{l}22.2 \\
32.2 \\
53.7 \\
57.9\end{array}$ & $\begin{array}{l}19.7 \\
28.3 \\
48.1 \\
52.7\end{array}$ & $\begin{array}{l}20.6 \\
29.8 \\
50.6 \\
55.1\end{array}$ & $\begin{array}{l}20.9 \\
28.2 \\
48.1 \\
52.7\end{array}$ & $\begin{array}{l}19.2 \\
28.6 \\
47.8 \\
52.7\end{array}$ & $\begin{array}{l}22.0 \\
30.5 \\
49.8 \\
53.7\end{array}$ \\
\hline "Polarization coefficient" ........................... & 0.408 & 0.454 & 0.431 & 0.463 & 0.462 & 0.440 \\
\hline
\end{tabular}

The results in table 3 for men generally accord with the widely held views that earnings inequality was higher in the United States than in Canada ${ }^{6}$ and that inequality has been increasing in both countries, ${ }^{7}$ though the data presented here are not directly comparable to data presented in earlier studies. One reason is that many studies focus on subsets of the population, such as those with full-time, year-round attachment to the labor force; or they consider hourly rather than annual earnings, and then only for one (possible "average") job, even if the individual had more than one over the year; or they exclude self-employment earnings. In contrast, the results presented in this article cover everyone with nontrivial attachment to the labor force on an annual basis, as well as all their incomes from working.

Another reason for the different conclusions may be the choice of statistical indicators. The inequality measures used here have been carefully selected from the viewpoint of "construct validity." They can never be inconsistent with orderings given by Lorenz curves, unlike widely used statistics such as the 90-10 percentile cut-off ratio, the logarithm of this ratio, or the variance of the logarithms. Moreover, one set of measures has been designed explicitly to measure polarization. ${ }^{8}$ 
In any case, there are interesting differences in trends between Canada and the United Sates. Virtually all the growth in earnings inequality in Canada occurred during the 1974-85 period, with apparently no statistically significant changes ${ }^{9}$ between 1985 and 1995, although the quintile shares indicate that the underlying Lorenz curves cross, so that unequivocal statements about earnings inequality trends are not possible.

From the last five rows in the section for men in table 3, it is clear that there was a decline in the number of "middle-class jobs" (or, more accurately, of men with middle-range earnings) from 1974 to 1985 in Canada, but, if anything, a slight increase from 1985 to 1995. For example, the proportion of men with earnings between 75 percent and 150 percent of the median fell significantly, from 46 percent of all effective labor force participants to 36 percent, between 1974 and 1985, but then remained essentially unchanged up to 1995 . This trend is reflected in the movements of the summary index of polarization, shown in the last row of this section of the table. (Higher values imply greater polarization.) In contrast, polarization increased for the U.S. men in both periods: in 1974, the number of "middle-class earners" was already lower than in Canada - 44 percent, compared with 46 percent, for those with earnings 75 percent to 150 percent of the median. The proportion of U.S. men with earnings in this range fell somewhat less than in Canada through 1985, but then it fell again, marginally, up to 1995, while Canada's figure remained static.

Charts 3 through 5 give more detail on the underlying changes in the income distributions in the two countries by showing decennial earnings growth rates at each point throughout the income spectrum. ${ }^{10}$ For example, the top panel of chart 3 shows that, for the first two-thirds of U.S. male effective labor force participants, real earnings fell over the 1974-85 period, while the bottom panel of chart 4 indicates that virtually all women in both countries had earnings growth of at least 10 percent per decade from 1985 to 1995.

When these "growth-rate curves" are monotonically increasing, it follows logically that the underlying Lorenz curves do not cross and that inequality is increasing. ${ }^{11}$ Interestingly, the curves shown in the charts are generally not monotonic (not even if they were "smoothed" to remove the effects of sampling variability and respondents' proclivity to report their incomes in rounded-off numbers), so that no rigorous statements about changes in inequality are possible.

For example, the bottom panel of chart 3 shows that, in both countries, men's earnings inequality over the 1985-95 period generally increased for the first 15 percent of the population, fell over the next 15 percent or so, was unchanged for the next 30 percent or 40 percent, and increased for the remaining population. Corresponding changes in quintile and decile shares are shown in table 3; not withstanding the changes in Gini coefficients in the table (increasing by about 0.04 in the United Sates and about one-fourth as much in Canada), the bottom panel of chart 3 shows qualitatively very similar patterns of change in the two countries with the U.S. and Canadian growth-rate curves nearly superimposed on each other. ${ }^{12}$ 
Chart 3. Decennial growth rates in earnings by $M$-tile, Canada and United States, male effective labor force participants aged 18 to $64,1974-1995$

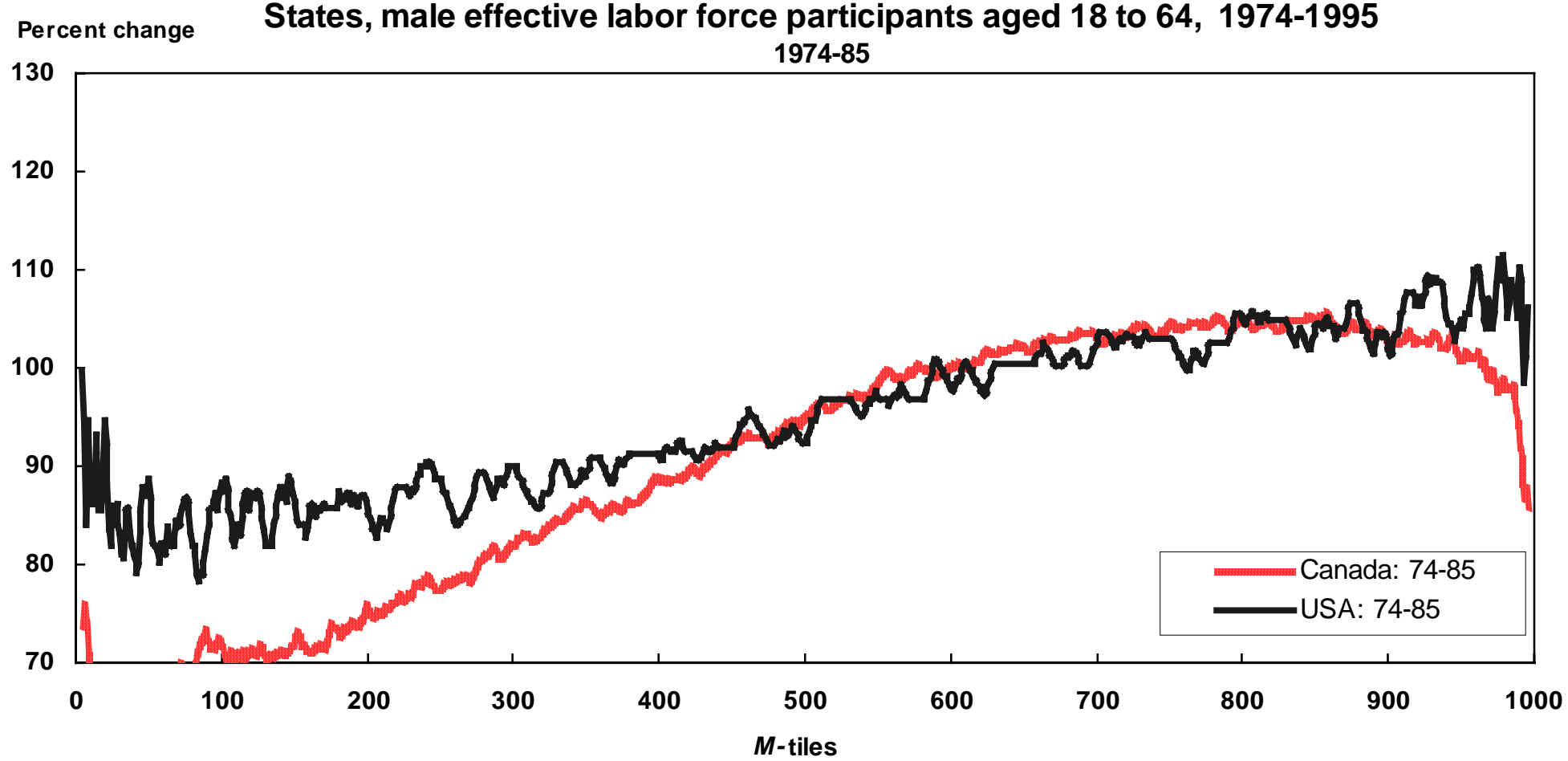

Percent change

1985-95

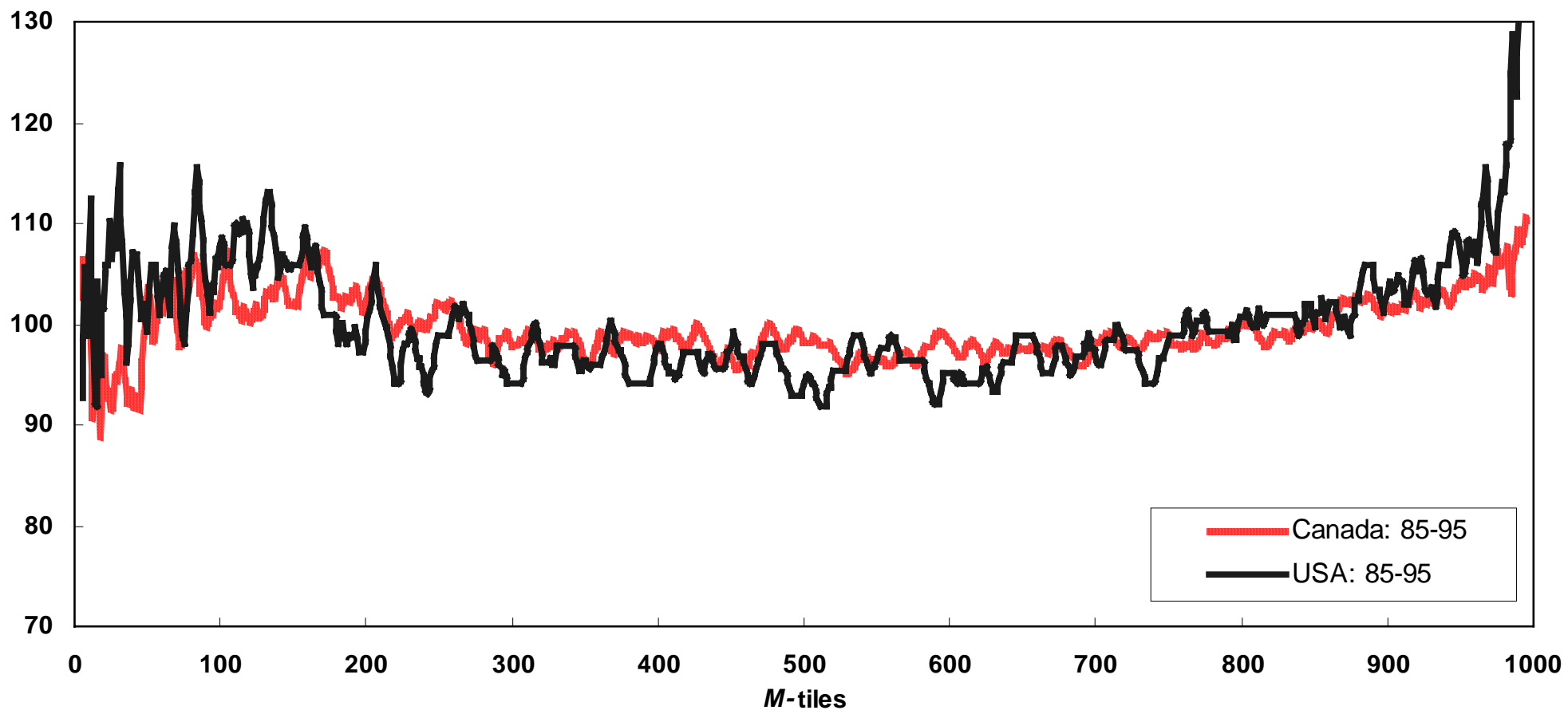

Note: Individuals are arrayed along horizontal axis in terms of tenths of a percent of population, or $M$-tiles. Vertical axis is decennial percent change in earnings for each $M$-tile, from first to second earnings distribution (in own-country constant dollars). 
Chart 4. Decennial growth rates in earnings by $M$-tile, Canada and United States, female effective labor force participants aged 18 to 64, 1974-1995

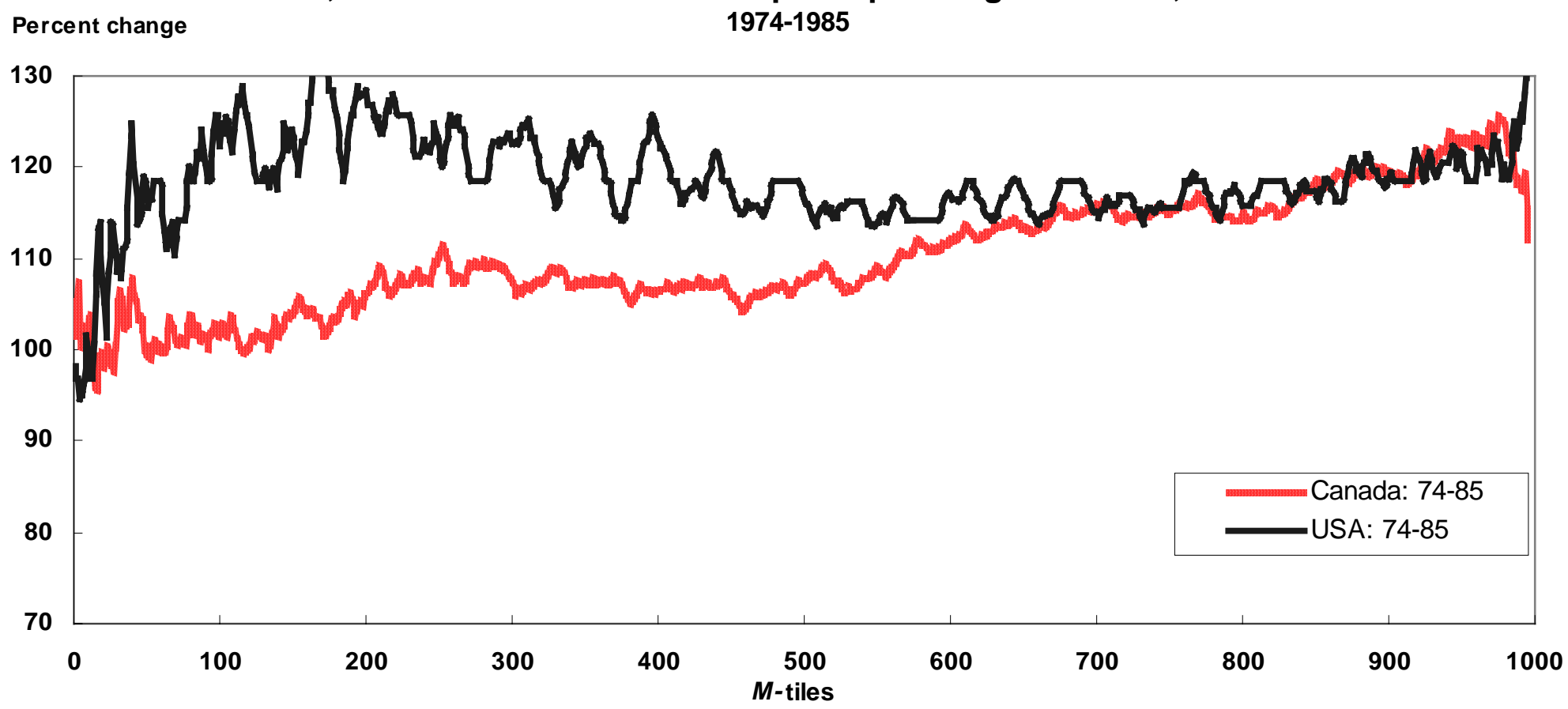

Percent change

1985-1995

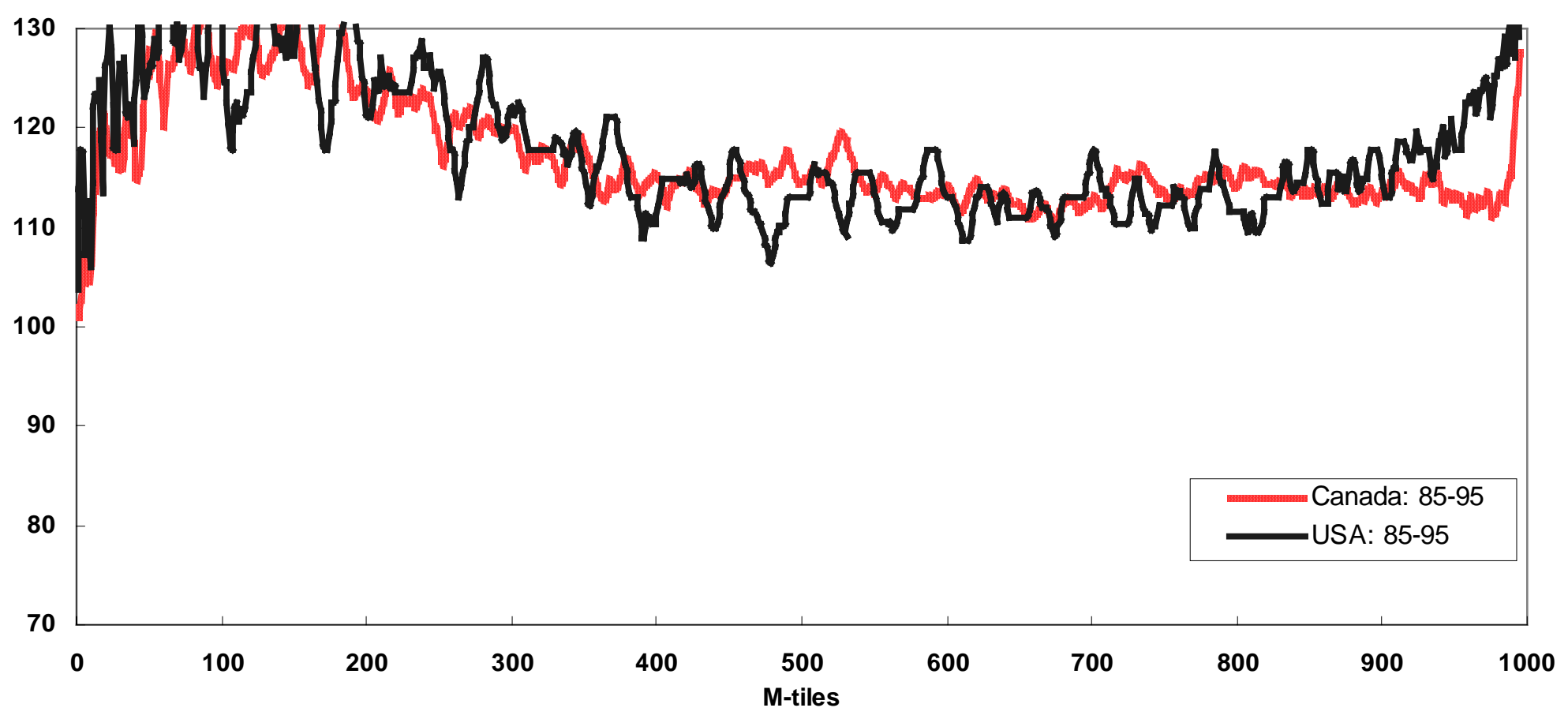

NOTE: Individuals are arrayed along horizontal axis in terms of tenths of a percent of population, or $M$-tiles. Vertical axis is decennial percent change in earnings for each $M$-tile, from first to second earnings distribution (in own-country constant dollars). 
Chart 5. Decennial growth rates in earnings by $M$-tile, Canada and United States, all effective labor force participants aged 18 to $64,1974-1995$
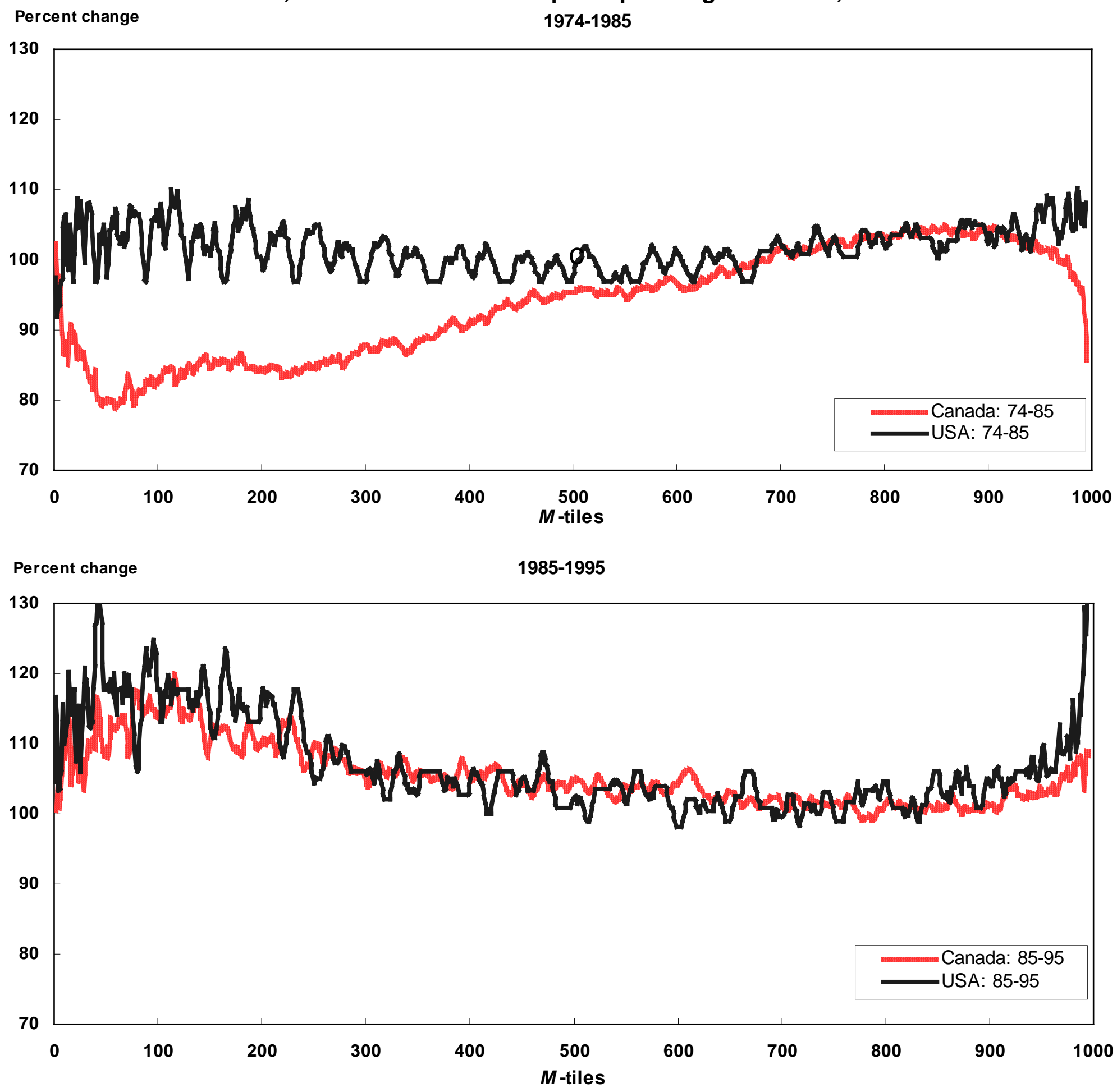

NOTE: Individuals are arrayed along horizontal axis in terms of tenths of a percent of population, or $M$-tiles. Vertical axis is decennial percent change in earnings for each $\mathrm{M}$-tile, from first to second earnings distribution (in own-country constant dollars). 
U.S. income minus Canadian income

Chart 6. Difference in income, Canada and United States, all effective labor force participants, aged 18 to 64, in 1995 Canadian dollars, based on Statistics Canada purchasing power parities, 1974, 1985 and 1995

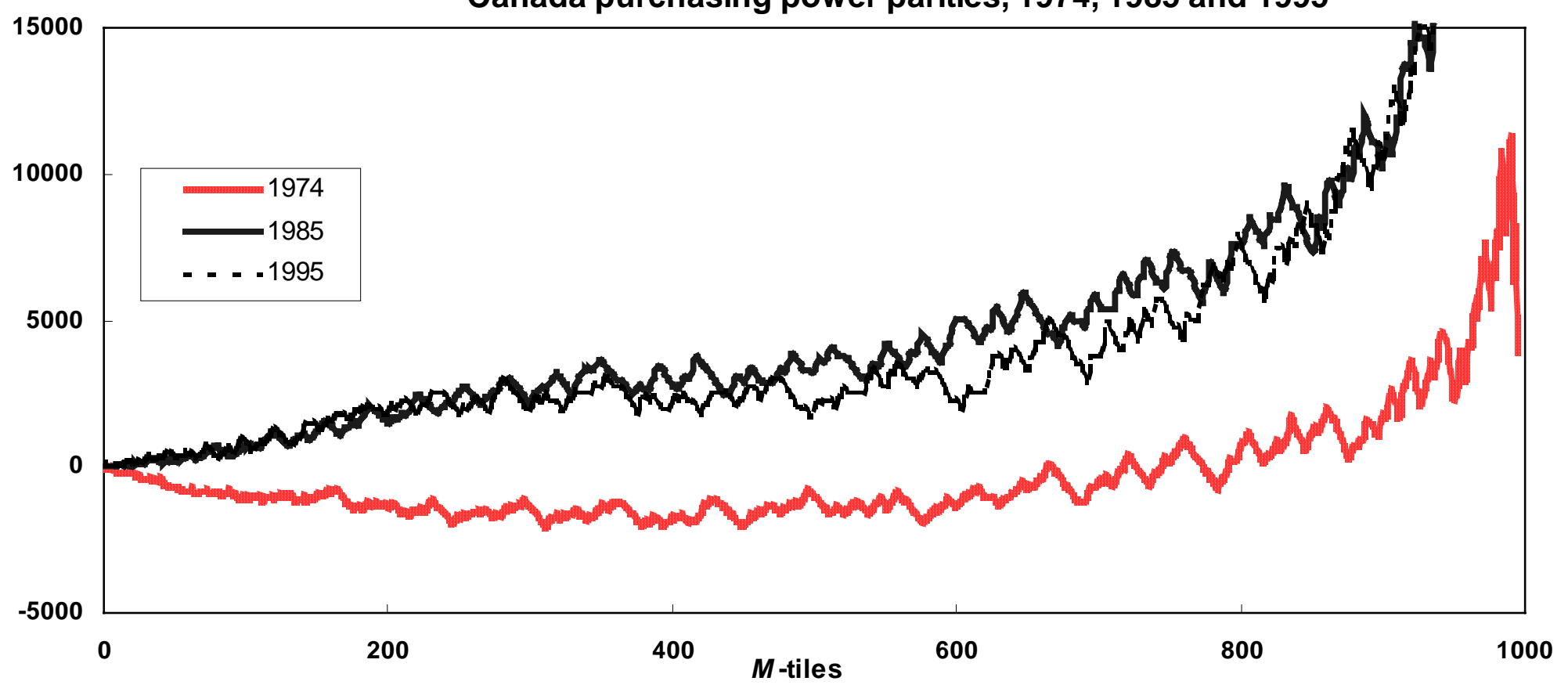

Chart 7. Difference in income, Canada and United States, all effective labor force participants, aged 18 to 64, in 1995 Canadian dollars, based on Penn World Table purchasing power parities, 1974, 1985 and 1995

U.S. income minus

Canadian income

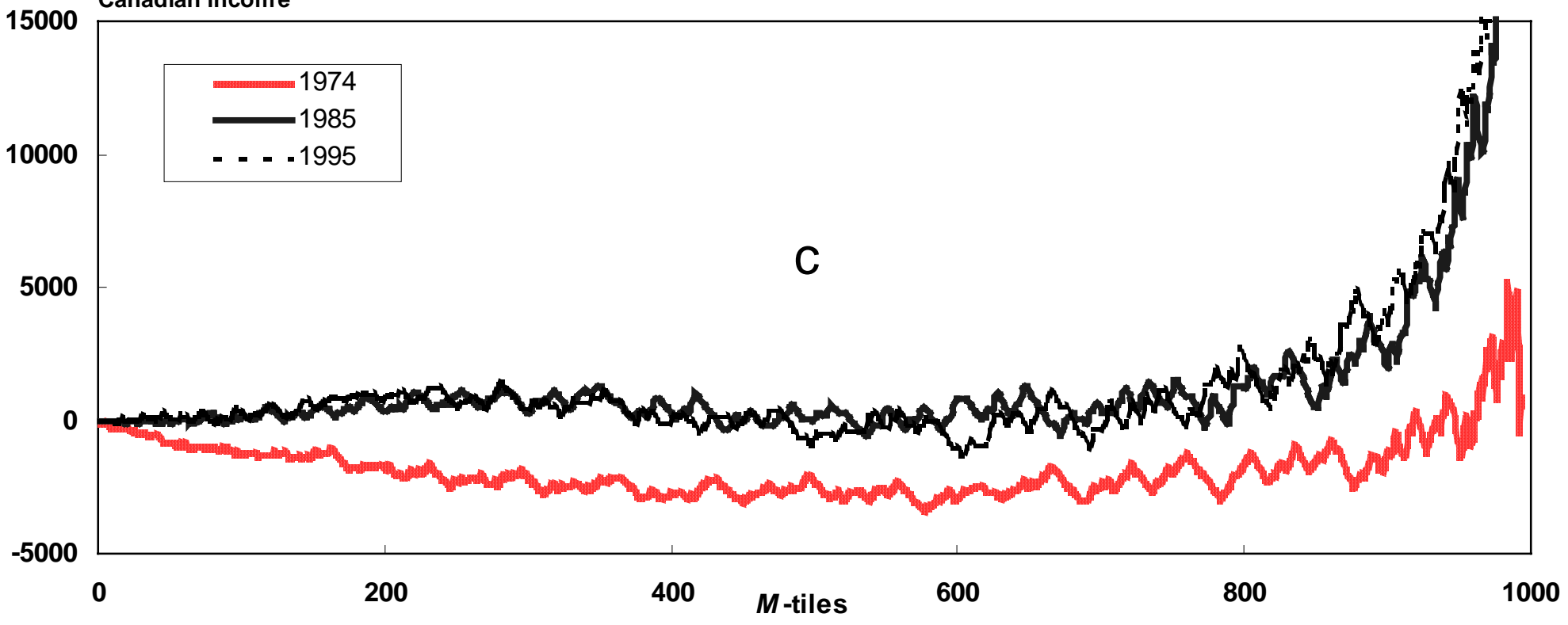

NOTE: In Charts 6 and 7, individuals are arrayed along horizontal axis in terms of tenths of a percent of population, or M-tiles. Vertical axis is absolute difference in income for each M-tile. 
In contrast, the top panel of chart 3 shows that the two countries' growth-rate curves for men were quite dissimilar over the 1974-85 period. The United States had an unequivocal increase in earnings inequality for male effective labor force participants throughout almost the entire earnings spectrum (the bottom decile being the main exception), while in Canada, earnings inequality for men increased at a sharper rate than in the United States for most of the earnings spectrum, although it declined within the upper decile. The chart shows generally monotonically increasing growth rates for the middle 80 percent of the population of male effective labor force participants for both countries, but a somewhat lower slope in the United States, except in the uppermost tail of the earnings distribution.

The second section of table 3 and both panels of chart 4 show the corresponding statistics for women. In the table, the quintile and decile shares indicate that the underlying Lorenz curves were crossing. This is also evident from the chart, in which the growth-rate curves are definitely not monotonic, so no general statement about the changes in earnings inequality among women is possible for either country, for either decade. As was the case for men, growth-rate curves for women were dissimilar over the 1974-85 period, but similar in shape for 1985-95.

Polarization of women's earnings, however, was unambiguous in Canada, rising from 1974 to 1985 and then falling. In the United States, the underlying polarization curves (the analogue of the Lorenz cure for making unequivocal judgements) cross at about $90^{\text {th }}$ percentile, so no general statements are possible. Nevertheless, table 3 indicates a rather general increase in midlevel U.S. female earners from 1974 to 1985 (relative to their median) and a more ambiguous increase from 1985 to 1995.

Comparing men's with women's earnings in charts 3 and 4, we readily see that one major difference is the generally higher growth rates of women's earnings, not only at each point in time, but also virtually throughout the earnings spectrum. The other major difference is in the slopes of the curves: for men, the generally positive slopes indicate an increase in inequality, while for women, the curves have more pronounced regions of downward slopes.

Of course, the labor market is not completely segregated by sex, so it is appropriate to look at the earnings distributions for the entire population of effective labor force participants. These results are shown in the last two sections of table 3 and in chart 5, for those aged 18 to 64 . As indicated by the nonmonotonic curves in the chart, as well as the conflicting movements in quintile and decile shares shown in the corresponding section of the table, the underlying Lorenz curves for Canada and the United States cross for both decades' changes. Nevertheless, inequality generally increased from 1974 to 1985 in both countries, more so in Canada.

Perhaps surprisingly, polarization appears to have fallen in Canada and in the United States over the 1985-95 period, after rising in both countries during 1974-85. Inspection of the underlying curves shows that the decline in polarization in Canada was unambiguous, but that the U.S. curves cross at about the $90^{\text {th }}$ percentile. Except for this upper tail, however, the data indicate that the number of "middle-class" earners increased in the United Sates, even though inequality also increased.

The last block of rows in table 3 broadens the population to consider everyone aged 15 or older who was an effective labor force participant. ${ }^{13}$ The data in these rows show ambiguous changes in inequality, because the Lorenz curves cross. But for the United States, as well as Canada, there is an unambiguous increase in the number of "middle-class" earners from 1985 to 1995. For the United States, this increase is contrary to virtually all discussions in the literature. The basic reason is that U.S. analyses use only inequality indicators, so they are unable to notice 
trends in polarization, or the "disappearance of the middle class, " as it is generally understood.

As a final look at individual earnings, charts 6 and 7 provide comparisons of levels of earnings throughout the distribution between Canada and the United States for the population of effective labor force participants aged 18 to 64. Chart 6 uses Statistics Canada's measure of purchasing power parity, which is conceptually, the most appropriate. However, the Penn World Table's measures are much more widely used in macroeconomic analysis, as well as in virtually all cross-national studies of inequality. ${ }^{14}$ Thus, to give an indication of the sensitivity of the results to the choice of purchasing power parity, and because the two measures bracket the range discussed in the appendix, chart 7 shows the same comparison using the Penn World Table purchasing power parities (in both cases, for the personal final expenditure component of GDP).

Using Statistics Canada's bilateral purchasing power parities, chart 6 shows that in 1974, the first 80 percent of Canadian earners were absolutely better off than their U.S. counterparts. But by 1985 , U.S. earners were all better off than their Canadian counterparts, generally by as much as 10 percent to 20 percent although the extent of this advantage was somewhat reduced in 1995. If, on the other hand, the Penn World Table purchasing power parities are used, as in chart 7 , the first 80 percent of earners in the two countries were essentially equal in the effective purchasing power of their earnings in 1985 and in 1995. In the latter year, U.S. earners were at least $\$ 500$ better off than their Canadian counterparts only above the $90^{\text {th }}$ percentile and more than $\$ 10,000$ better off only above the $95^{\text {th }}$ percentile.

\section{Family disposable income}

This section examines sets of statistical indicators for family disposable income similar to those examined for individual earnings in the previous section. (See appendix for definitions of family and disposable income.)

Mean and median incomes. Table 4 shows mean and median levels of disposable family income. Families include both unattached individuals and families with two or more members. Results are given in own-country constant dollars, as well as in Canadian dollars, using the Statistics Canada and Penn World Table purchasing power parities for personal final expenditure.

Average family disposable income was approximately $\$ 35,000$ in Canada in 1995 . The corresponding U.S. figure was either about the same or $\$ 4,000$ higher, depending on the measure of purchasing power parity used. For median disposable family income, U.S. levels ranged from a few hundred dollars higher to almost $\$ 3,000$ lower, again depending on the choice of purchasing power parity in 1995. Indeed, the only cases in which the U.S. median was above the Canadian median disposable income were in 1985 and 1995, for income converted using the Statistics Canada bilateral purchasing power parity. This general result, that up to roughly the halfway mark in the income spectrum Canadian families were better off, is particularly striking, given the prevailing view that Canada has a considerably higher level of taxation than does the United States.

One caveat is that these results omit several major sources of in-kind government benefits, particularly publicly funded health care services. While many U.S. families regularly have to spend hundreds of dollars per month for private health insurance, Canadians have no such obligation. According to Smeeding and colleagues, ${ }^{15}$ in the early 1980 s (the most recent period for which any international comparison was made of the distributional impacts of in-kind public services), Canada's universal public health care system was larger and distributionally more 
progressive. Thus, had the value of publicly provided health care benefits been included in the analysis, Canadian family income levels would have moved higher relative to those of U.S. families, and inequality would have fallen more in Canada.

\begin{tabular}{|c|c|c|c|c|c|c|}
\hline \multicolumn{7}{|c|}{$\begin{array}{l}\text { Mean and median family disposable income, in thousands of dollars, Canada and United States, } \\
1974,1985 \text { and } 1995\end{array}$} \\
\hline [in percent] & & & & & & \\
\hline \multirow[b]{2}{*}{ Category } & \multicolumn{3}{|c|}{ Canada } & \multicolumn{3}{|c|}{ United States } \\
\hline & 1974 & 1985 & 1995 & 1974 & 1985 & 1995 \\
\hline \multirow{4}{*}{ 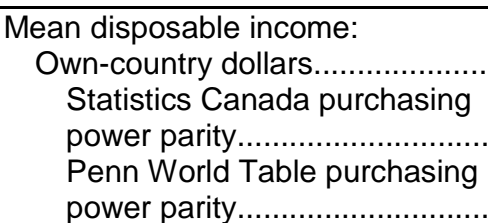 } & & & & & & \\
\hline & 34.8 & 36.5 & 35.2 & 29.6 & 30.0 & 31.6 \\
\hline & 34.8 & 36.5 & 35.2 & 32.6 & 38.7 & 39.5 \\
\hline & 34.8 & 36.5 & 35.2 & 30.7 & 33.7 & 35.3 \\
\hline \multirow{4}{*}{ 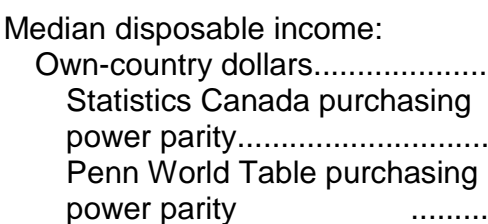 } & & & & & & \\
\hline & 31.5 & 32.0 & 30.2 & 25.8 & 24.9 & 24.6 \\
\hline & 31.5 & 32.0 & 30.2 & 28.4 & 32.1 & 30.8 \\
\hline & 315 & 320 & 302 & 26.8 & 280 & 275 \\
\hline
\end{tabular}

\section{Table 5.} Inequality and polarization indicators for family disposable income, adjusted for size and composition of family, 1974, 1985 and 1995

[in percent]

\begin{tabular}{|c|c|c|c|c|c|c|}
\hline \multirow[b]{2}{*}{ Quintile or decile and indicator } & \multicolumn{3}{|c|}{ Canada } & \multicolumn{3}{|c|}{ United States } \\
\hline & 1974 & 1985 & 1995 & 1974 & 1985 & 1995 \\
\hline \multicolumn{7}{|l|}{ Indicators of inequality: } \\
\hline 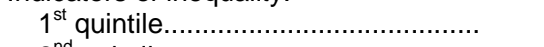 & 6.1 & 7.1 & 7.5 & 5.6 & 5.0 & 4.7 \\
\hline 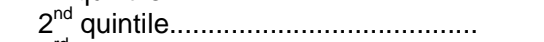 & 12.9 & 12.9 & 13.1 & 12.2 & 11.4 & 10.9 \\
\hline 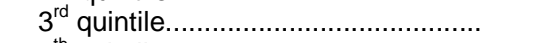 & 18.3 & 17.9 & 17.8 & 17.7 & 17.4 & 16.5 \\
\hline 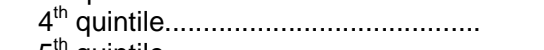 & 24.1 & 23.8 & 23.5 & 24.2 & 24.5 & 23.7 \\
\hline $5^{\text {th }}$ quintile & 38.5 & 38.3 & 38.1 & 40.2 & 41.7 & 44.2 \\
\hline 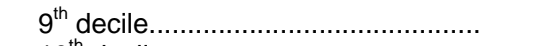 & 15.3 & 15.2 & 15.1 & 15.9 & 16.4 & 16.1 \\
\hline 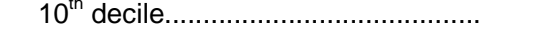 & 23.2 & 23.1 & 23.0 & 24.4 & 25.4 & 28.0 \\
\hline 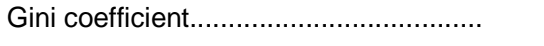 & .324 & .313 & .306 & 346 & .368 & 394 \\
\hline \multicolumn{7}{|l|}{$\begin{array}{l}\text { Indicators of polarization } \\
\text { (percent of median) }\end{array}$} \\
\hline 75-125 & 33.9 & 33.6 & 35.0 & 30.6 & 27.9 & 26.8 \\
\hline 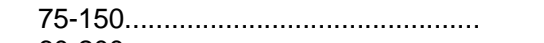 & 46.6 & 45.9 & 47.3 & 42.0 & 38.5 & 36.9 \\
\hline 60-200 & 69.3 & 71.2 & 72.8 & 65.3 & 61.1 & 60.0 \\
\hline 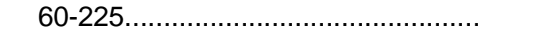 & 72.1 & 74.2 & 75.9 & 68.9 & 65.0 & 63.9 \\
\hline "Polarization coefficient"............................... & 271 & 272 & 264 & 304 & .334 & 350 \\
\hline \multicolumn{7}{|l|}{ Percent of median: } \\
\hline 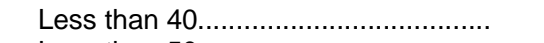 & 10.9 & 8.6 & 7.3 & 12.4 & 14.3 & 13.7 \\
\hline 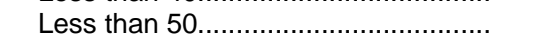 & 17.5 & 13.6 & 12.1 & 18.2 & 20.5 & 19.8 \\
\hline 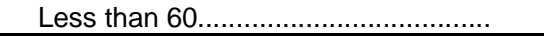 & 23.2 & 20.7 & 18.8 & 24.3 & 26.5 & 26.1 \\
\hline
\end{tabular}


Chart 8. Decennial growth rates ion family disposable income, adjusted for family size and composition, by M-tile, Canada and United States, 1974-1995

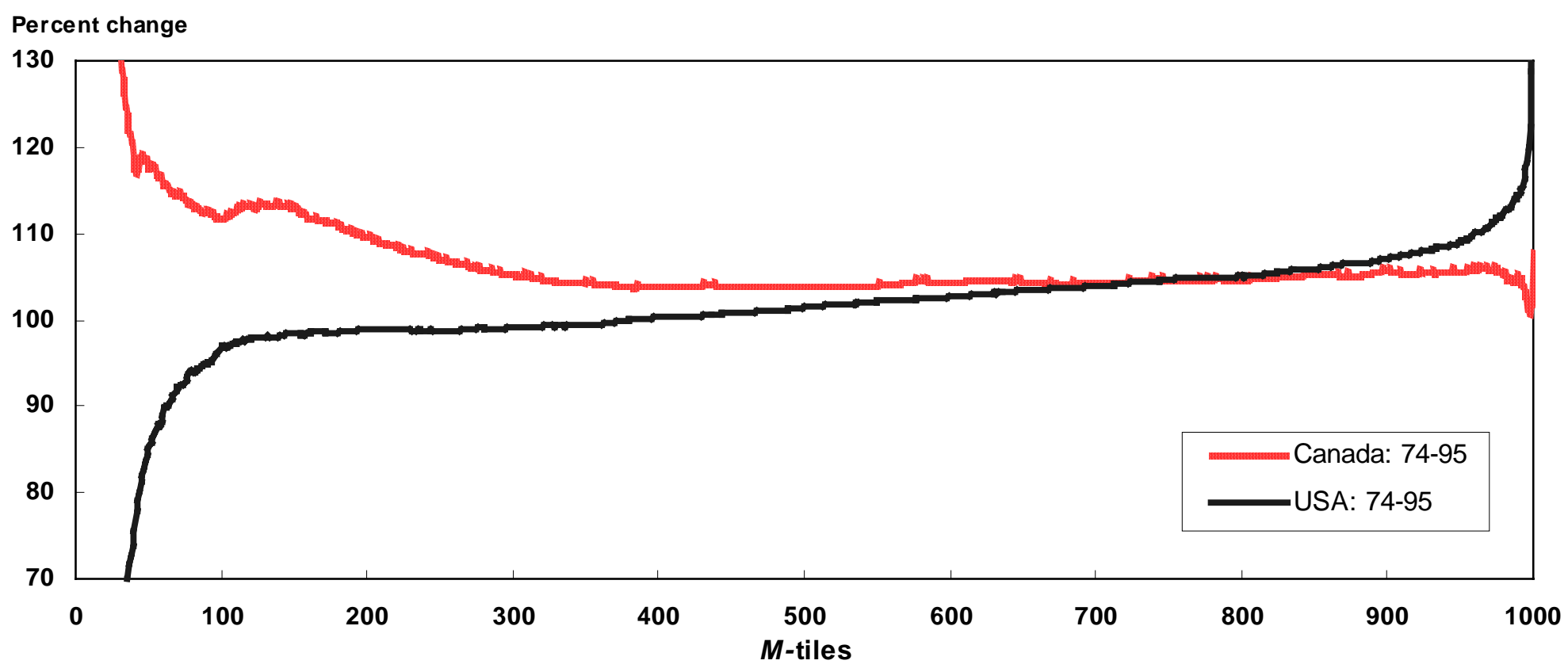

NOTE: Individuals are arrayed along horizontal axis in terms of tenths of a percent of population, or M-tiles.

Chart 9. Difference in family disposable income adjusted for size and composition, Canada and United States, in 1995 Canadian dollars, based on

U.S. income minus Statistics Canada purchasing power parities, 1974, 1985 and 1995 Canadian income

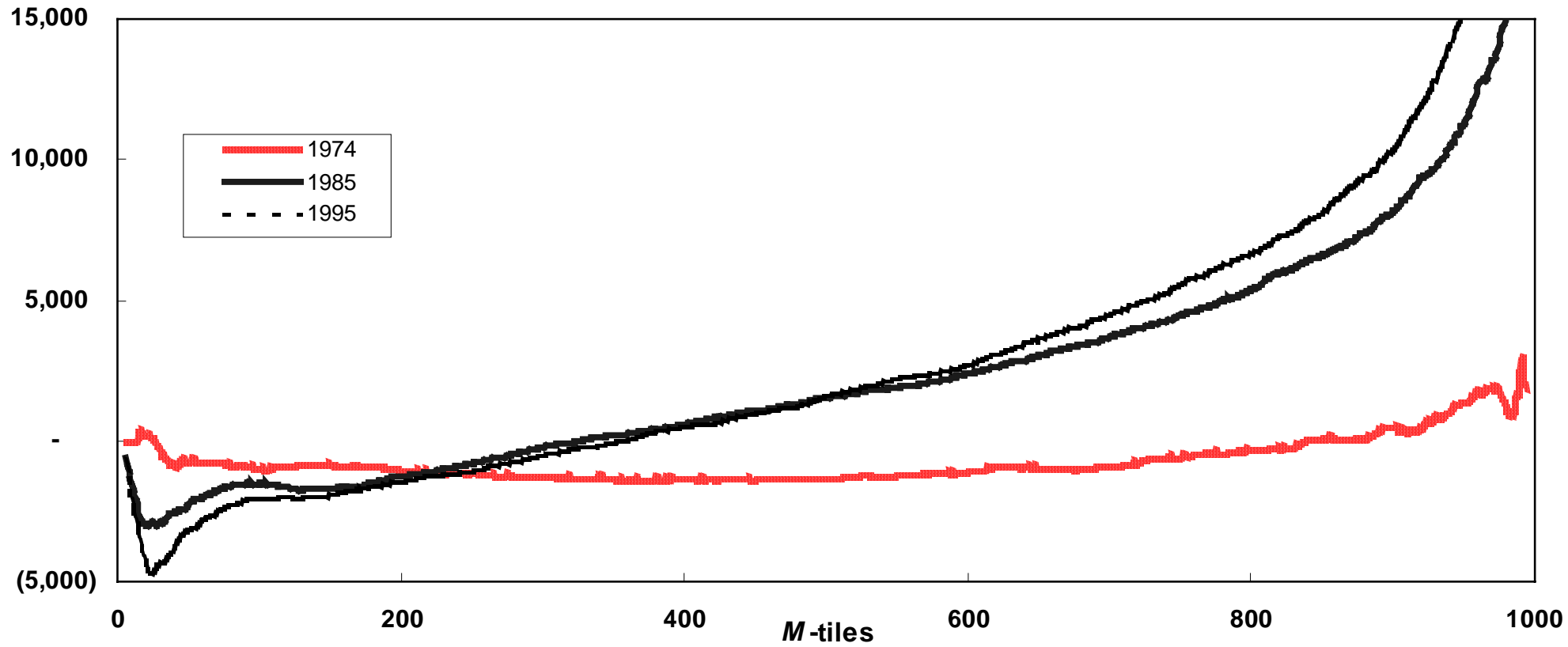

NOTE: Individuals are arrayed along horizontal axis in terms of tenths of a percent of population, or $M$-tiles. Vertical axis is absolute difference in income for each $M$-tile. 


\section{Chart 10. Difference in family disposable income adjusted for size and composition, Canada and United States, in 1995 Canadian dollars, based on Penn World Table purchasing power parities, 1974, 1985 and 1995}

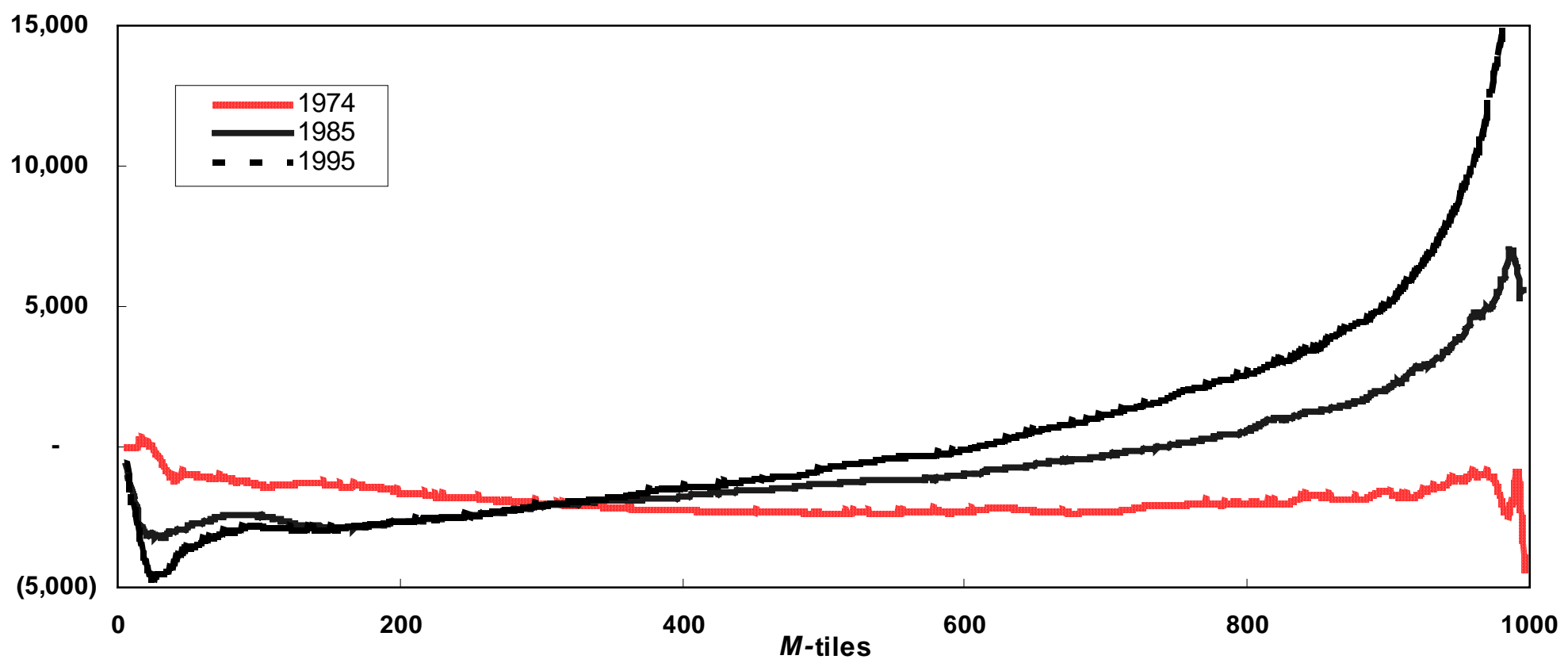

NOTE: Individuals are arrayed along horizontal axis in terms of tenths of a percent of population, or $M$-tiles. Vertical axis is absolute difference in income for each $M$-tile.

Family disposable income inequality and polarization. Table 5 and chart 8 show the same series of indicators of polarization and inequality as was presented for individual earnings, but this time for family disposable income, adjusted for family size and composition by means of an equivalence scale. ${ }^{16}$ The chart and the table indicate a most dramatic contrast between Canada and the United States: there was an unequivocal increase in income inequality in the United States over both decades, ${ }^{17}$ while there was an almost unequivocal decrease in inequality in Canada, based not only on the indicators shown in the table, but also on the underlying Lorenz curves.

With regard to polarization, the results shown in table 5 must be tempered by the fact that the underlying polarization curves cross for the 1974-85 period in Canada, although they give almost unequivocal results for Canada from 1985 to 1996 and for the United States during both periods. Thus, polarization of family income, adjusted for size and composition, fell in Canada from 1985 to 1995, but rose in both decades in the United States. For example, the proportion of Canadian "middle-class" families (those with incomes between 75 percent and 150 percent of the median) increased from about 46 percent to about 47 percent from 1985 to 1995, while the corresponding proportion in the United States fell from about 38 percent to about 37 percent during the same period. These trends over the two decades combined are shown in the growthrate curves of chart 8 , in which the contrast between the two countries could not be more evident: the Canadian curve is almost everywhere monotonically decreasing, while the curve for the United States is everywhere monotonically increasing.

Chart 9 and the left side of table 6, based on the Penn World Table purchasing power 
parity, show Canadian families absolutely better off than their U.S. counterparts in terms of sizeand composition-adjusted disposable 1995 income up to about the $61^{\text {st }}$ percentile. ${ }^{18}$ If, instead, the Statistics Canada bilateral purchasing power parities are used (chart 10 and the right side of table 6), approximately 36 percent of Canadian families have absolutely higher real disposable incomes than their U.S. counterparts.

Finally, the last three rows of table 5 show the proportions of families whose size- and composition-adjusted disposable income was less that 40 percent, 50 percent, and 60 percent, respectively, of the similarly adjusted median family income. The proportions at the 50-percent level correspond to a very widely used measure of "income poverty": those with incomes less than half the (family size-adjusted) median. Thus, the row labeled "less than 40 percent" can be thought of as marking the incidence of "poverty" using four-fifths of the usual "poverty line, " while the row labeled "less than 60 percent" gives the incidence using 120 percent of this "poverty line."

These numbers also show some surprising results. In Canada, the proportions below all three of the lines fell over both decades examined. And while the incidence of "income poverty" rose in the United States over the 1974-85 period, it, too, fell, albeit marginally, between 1985 and $1995 .{ }^{19}$ The latter result is particularly striking, especially given the rising rates of officially measured poverty in the United States. However, the data in table 5 are based on relative measure of low income, while the official U.S. poverty statistics are based on an absolute poverty line.

One factor that does not account for this U.S. trend is an increase in incomes at the bottom of the income spectrum; indeed table 5 shows the share of the bottom income quintile falling by about one-third of a percentage point. Rather, as indicated in table 4, median family disposable income (albeit unadjusted for family's size and composition) fell by about $\$ 300$ (in U.S. dollars) from 1985 to 1995, thereby lowering the half-median low-income cut-off point.

This analysis has presented a detailed description of comparative trends in income inequality in Canada and the United States. In addition, income polarization, which differs conceptually from income inequality, has been examined.

A principal conclusion of the analysis is that the conventional wisdom which holds that the United States is both a richer and a more unequal society than Canada is only partly correct. As regards the labor market, both countries show some similarities. Both experienced substantial increases in the proportions of working-age women who were effective labor force participants (defined simply by the receipt of more than $\$ 500$ (1995 Canadian dollars) in earnings of the year), as well as increases in the average levels of women's earnings. Also, both countries saw falling median earnings for men over the two decades covered in the analysis. However, while the average earnings of Canadian men fell over the entire period, those of their U.S. counterparts fell from 1974 to 1985 , but then rose from 1985 to 1995 . This seeming paradox of differential movements of the mean and median over the last decade in the United States is explained by a sharp rise in U.S. male earnings inequality over both decades. In contrast, while male earnings inequality rose from 1974 to 1985 in Canada, it was generally unchanged from 1985 to 1995.

Examining the labor market as a whole - that is, considering male and female effective labor force participants together - yields another striking result: while U.S. earnings inequality rose from 1985 to 1995 , as per the conventional wisdom, U.S. earnings polarization fell over this same period. In other words, the proportion of "middle class earners" increased in the United States over the last decade. (Both earnings inequality and earnings polarization fell slightly in 
Canada over the period, after both had risen during the previous decade.) The reason this fall in U.S. earnings polarization seems not to have been noticed is that, while U.S. analysts were among the first to detect the "disappearing middle class" in studies published in the mid-1980s, ${ }^{20}$ more recent analyses have focused only on measures of inequality.

With respect to family incomes, the most striking result is that a substantial fraction of Canadian families was absolutely better off in 1995 than their U.S. counterparts at similar points in the income spectrum. However, one must be cautious here because this result depends critically on the measures of purchasing power parity used to equate Canadian and U.S. currencies. On the basis of the most widely used measures, those of the Penn World Table, ${ }^{21}$ about 60 percent of Canadians (ranked in terms of their family disposable incomes, adjusted for family structure) have higher incomes that their similarly defined U.S. counterparts. ${ }^{22}$ On the other hand, Statistics Canada's measures of purchasing power parity, which are conceptually more appropriate in this context, still result in more than the first 35 percent of families in the Canadian income distribution being economically better off than families in the corresponding portion of the U.S. income spectrum.

Finally, the two decades of Canada-U.S. comparisons suggest that, when viewed through the lenses of the statistical measures highlighted in this article, the two countries' labor markets are becoming more similar. The pattern of changes in the earnings distribution shown in charts 3 , 4 , and 5 are much more similar over the $1985-95$ period than over the $1974-85$ period. This convergence in labor market trends contrasts with the more usual impressions left, for example, by comparisons of official unemployment rates or published analyses of comparative inequality trends.

\begin{tabular}{|c|c|c|c|c|c|c|}
\hline \multirow[t]{3}{*}{ Differences in familv dis } & $\begin{array}{l}\text { able in } \\
74,198\end{array}$ & $\begin{array}{l}\text { e, }{ }^{1} \text { adju } \\
\text { d 1995 }\end{array}$ & for siz & comp & of fan & \\
\hline & \multicolumn{3}{|c|}{ Penn World Table } & \multicolumn{3}{|c|}{ Statistics Canada } \\
\hline & 1974 & 1985 & 1995 & 1974 & 1985 & 1995 \\
\hline 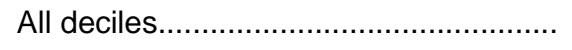 & -10.1 & -10.9 & -8.2 & -4.7 & 2.2 & 2.7 \\
\hline $1^{\text {st }}$. & -4.7 & -48.7 & -61.8 & .3 & -41.7 & 57.3 \\
\hline $2^{\text {nd }} .$. & -15.5 & -26.0 & -25.9 & -10.4 & -15.1 & -17.1 \\
\hline $3^{\text {rd. }}$. & -15.0 & -18.0 & -17.5 & -9.8 & -6.0 & -7.7 \\
\hline $4^{\text {th }} \ldots$ & -14.2 & -12.0 & -10.9 & -9.0 & 1.0 & -.4 \\
\hline 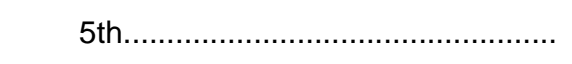 & -12.9 & -8.1 & -6.2 & -7.6 & 5.4 & 4.9 \\
\hline 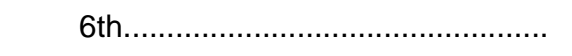 & -11.3 & -5.3 & -1.9 & -6.0 & 8.6 & 9.7 \\
\hline 7th. & -9.6 & -2.6 & 2.1 & -4.2 & 11.7 & 14.2 \\
\hline $8^{\text {th }} \ldots$ & -7.8 & .3 & 6.4 & -2.2 & 15.0 & 19.0 \\
\hline $9^{\text {th }} \ldots$ & -5.8 & 3.6 & 10.6 & .0 & 18.8 & 23.7 \\
\hline $10^{\text {th }} \ldots \ldots \ldots \ldots \ldots . . . . .$. & -3.8 & 7.3 & 22.2 & 2.0 & 23.1 & 36.7 \\
\hline
\end{tabular}


However, as shown in chart 8 , no such claim can be made for the convergence of Canadian and U.S. income tax and transfer policy. Canada continues to differ significantly from the United States, particularly in the economic positions of those in the bottom 10 percent and top 5 percent of the income spectrum: the economic position of the poorest in Canada improved, while that of the poorest in the United States deteriorated; and, in contrast, the incomes of the most well off in Canada grew more slowly that the Canadian average, while the most well off in the United States fared much better than average over the past decade. Thus, while the results presented in this article suggest a convergence in patterns of change in earnings distributions in Canada and the United States over the last two decades, there has been no similar convergence in the effects of taxation and transfer policies up to 1995.

\section{Footnotes}

${ }^{1}$ In this and the following section, all results are derived from special tabulations and analyses of detailed microdata from the Survey of Consumer Finance in Canada and the March supplement to the Current Population Survey (CPS) in the United States. (See appendix for details.)

${ }^{2}$ The three years shown have been selected to span two decades, to end with the most recent data available, and to represent similar points in the business cycle. Data for additional years would be desirable, but, as will be seen, would greatly complicate the presentation. Moreover, based on other studies (see for example, Karoly, "Changes in the Distribution of Individual Earnings in the United States: 1967-1986," Review of Economics and Statistics, February 1992, pp. 107-15; and two articles in the December 1997 issue of the Monthly Labor Review: Jared Berstein and Lawrence Mishel, "Has wage inequality stopped growing?" pp. 3-16; and Robert I. Lerman, "Reassessing trends in U.S. earnings inequality," pp. 17-25), as well as our examinations of detailed annual Canadian data, choosing other points in time would not change the general conclusions of this article.

${ }^{3}$ The Canadian figures are expressed in constant dollars using the Consumer Price Index (CPI); for the United States, the official CPI is used for post-1982 data, while the "experimental" index based on current methodology is used for pre-1982 data. Amounts are rounded to reflect, generally, the maximum number of digits that are statistically significant, given sample variability. Figures in the text may differ from those in the table due to rounding.

${ }^{4}$ The $\$ 500$ amount corresponds roughly to 2 weeks working full time at the minimum wage in Canada in 1995. U.S. minimum thresholds were based on the same (Canadian) $\$ 500$ amount, converted to U.S. dollars using the 1995 Statistics Canada personal final expenditure purchasing power parities and then deflated using the U.S. CPI (See table A3 in appendix.)

${ }^{5}$ This relationship suggests a need for further exploration to account for the differential trends in these two approaches to measuring the extent of labor force participation.

${ }^{6}$ See, for example, M.L. Blackburn and D.E. Bloom, “The Distribution of Family Income: Measuring and Explaining Changes in the 1980s for Canada and the United States," in D. Card and R.B. Freeman, Eds. Small Differences That Matter: Labor Markets and Income Maintenance in Canada and the United States (Chicago and London, University of Chicago Press, 1993), pp. 233-65.

${ }^{7}$ See, for instance, R. Morissette, J. Myles and G. Picot, What is Happening to Earnings Inequality in Canada? Analytical Studies Branch Research Paper Series, no. 60 (Ottawa, Ontario, Statistics Canada, 1994); S.J. Davis, "Cross-country Patterns of Change in Relative Wages," in O.J. Blanchard and S. Fischer, Eds. NBER Macroeconomics Annual (Cambridge, MA, MIT Press, 1992), pp. 239-92; L. Karoly, "Anatomy of the U.S. Income Distributional Two Decades of Change," Oxford Review of Economic Policy, Spring 1996, pp. 76-95; C.Juhn, K.M. Murphy and B. Pierce, "Wage Inequality and the Rise in Returns to 
Skill," Journal of Political Economy, June 1993, pp. 410-42; Bernstein and Mishel, "Has wage inequality stopped growing?" and Lerman, "Reassessing Trends."

${ }^{8}$ See M.C. Wolfson, "Divergent Inequalities - Theory and Empirical Results," Review of Income and Wealth, December 1997, pp. 401-21.

${ }^{9}$ On the basis of a study by Kovacevic and Binder, Wolfson has provided detailed estimates of statistical significance for income inequality and polarization measures, taking account of the complex clustered sample design of the underlying Survey of Consumer Finance, the source for the Canadian data used in this article. The underlying U.S. data come from surveys with similarly complex sample designs. Thus, while formal estimates of sampling variability have not been generated for the analysis that is presented, the conclusions are those which would be statistically significant if variances similar to the ones found in the earlier study had applied (See Wolfson, "Divergent Inequalities"; and M.S. Kovacevic and D.A. Binder, "Variance Estimation for Measures of Income Inequality and Polarization - the Estimating Equations Approach," Journal of Official Statistics, March 1997, pp. 41-58.

${ }^{10}$ These charts differ somewhat from the usual presentations, for example, by Karoly and by Juhn and colleagues. (See footnote 7.) First, the bottom and top 5 percent are not trimmed off. The top 5 percent of the population is usually omitted from analyses of U.S. earnings, due to the top coding of incomes on public-use data. This article, however, draws on internal U.S. Census Bureau microdata files, which are top coded at much higher levels of income. For example, based on the top-coding algorithm used by the Census Bureau in 1995, no more that one one-hundredth of the records in any percentile were top coded, except for the first and last percentiles, for which the percentage rises to more than four one-hundredths. Second, the article uses tenths of percents (" $M$-tiles"), rather than percentiles, so there is much more jaggedness in the curves. While this feature is partly due to sampling, it is far more importantly related to the propensities of survey respondents to round their incomes to the nearest $\$ 500$ or $\$ 1,000$, an important source of nonsampling error. (See G. Row and S. Gribble, "Income Statistics from Survey Data: Effects of Respondent Rounding," in Proceedings of the American Statistical Association, Section on Business and Economic Statistics (American Statistical Association, Alexandria, VA, 1994), pp. 77-82.)

${ }^{11}$ Unfortunately, there is no simple relationship between the shape of the percentile growth-rate curve and changes in polarization. For example, a monotonically increasing curve is associated with both an increase in inequality and an increase in polarization, but a bimodal growth-rate curve can also indicate increasing polarization, even though a bimodal pattern of growth rates throughout the income spectrum would imply crossing Lorenz curves and hence an ambiguous change in inequality.

${ }^{12}$ Also, the chart highlights the risks of drawing potentially misleading conclusions about trends from a single indicator such as the widely used ratio of the $90^{\text {th }}$ percentile to the $10^{\text {th }}$ percentile.

${ }^{13}$ Table A1 in the appendix shows the sizes of various age and population groups in Canada and the United States, while table A2 compares the age structures of the two populations.

${ }^{14}$ See, for example, P. Gottschalk and T.M. Smeeding, Empirical Evidence on Income Inequality in Industrialized Countries, working paper no. 157 (Syracuse, NY, Syracuse University, Maxwell School of Citizenship and Public Affairs, 1997).

${ }^{15}$ T.M. Smeeding, P. Saunders, J. Coder, S. Jenkins, J. Fritzell, A.J. M. Hagenaars, R. Hauser and M. Wolfson, "Poverty, Inequality, and Family Living Standards Impacts across Seven Nations: the Effects of Noncash Subsidies for Health, education and Housing," Review of Income and Wealth, September 1993, pp. 229-56.

${ }^{16}$ The scale uses the equivalencies embodied in Statistics Canada's Low Income Measure: 40 percent for second and subsequent adults and for first children in single-parent families, and 30 percent for children in 
all other circumstances. This equivalence scale is very close to one using the square root of family size for example, as used in Gottschalk and Smeeding, Empirical Evidence on Income Inequality, and in A.B. Atkinson, B.L. Rainwater, and T.M. Smeeding, Income Distribution in OECD Countries: Evidence from the Luxembourg Income Study (LIS), Social Policy Studies, no. 18 (Paris, Organization for Economic Cooperation and Development, 1995).

${ }^{17}$ See, for example, D.H. Weinberg, “Are the Rich Getting Richer and the Poor Getting Poorer?" Current Population Reports, series P60, no. 191 (Bureau of the Census, June 1996): also on World Wide Web site http://www.census.gov/....

${ }^{18}$ This result is in accord with Gottschalk and Smeeding, Empirical Evidence on Income Inequality, but contrary to these authors' "Cross-national Comparisons of Earnings and Income Inequality," Journal of Economic Literature, June 1997, pp. 633-87. Smeeding indicates that the former work is the one to be used (personal communication).

${ }^{19}$ A similar result was obtained in a recent study. (See "Income Distribution and Poverty in Selected Countries," DEELS/ELSA.WP1 (97) 1/ANN1 (Paris, Organization for Economic Cooperation and Development, Working Party on Social Policy, Oct. 23,1997), annex 1, table 5.1.

${ }^{20}$ See L. Thurow, "The Disappearance of the Middle Class," New York Times, Feb. 5, 1984, sect. 3, p. 2; and M. Blackburn and D.E. Bloom, "What is Happening to the Middle Class?" American Demographics, January 1985, pp. 18-25.

${ }^{21}$ R. Summers and A. Heston, "The Penn World Table (Mark 5): An Expanded Set of International Comparisons, 1950-1988," Quarterly Journal of Economics, May 1991, pp. 327-68.

${ }^{22}$ Similar results are presented in Gottschalk and Smeeding, Empirical Evidence on Income Inequality.

\section{APPENDIX: Data and methodology}

Data sources and definitions. All the detailed distributional data on earnings and family disposable income in this article were generated using detailed microdata from Statistics Canada's Survey of Consumer Finance and the U.S. Census Bureau's March Supplement to the Current Population Survey. In both cases, data from internal master files were used. One result is that top coding is much less stringent than on the public-use samples employed in most published analyses. (See footnote 10 in text.)

Family. The term "family" used for both countries in this study refers to persons residing together and related by blood, marriage, or adoption. In Canada, this unit is typically referred to as the economic family; the corresponding U.S. label is the census family or just the family. Note that a family, as defined in the text, includes families of only one person. In contrast, both Canada and the U.S. official family statistics refer to groups of two or more persons and exclude unattached individuals.

Earnings. Earnings are defined as wages and salaries from all jobs before deductions, plus selfemployment income from farm and non-farm sources. Earnings (particularly self-employment income) may be negative. In U.S. Census Bureau reports, earnings are referred to as total money earnings. Net income from roomers and boarders is included in earnings in Canada, whereas in the United States, it is included in investment income (although, at less than six hundredths of a percent of total income in aggregate, the difference is minor). Given the aforesaid definition of earnings, in order to be considered an effective labor force participant, a self-employed person with negative self-employment income would have to have sufficient wages to cover the loss in self-employment and still meet the $\$ 500$ criterion set forth in the text. 
Disposable income. For the United States, disposable income is defined as total money income (according to the official definition used in the U.S. Census Bureau reports), plus energy assistance grants in 1995, plus food stamps in 1985 and 1995, plus the earned income tax credit in 1985 and 1995, less State and local taxes, less Social Security deductions (FICA). For Canada, disposable income is defined as total money income (as defined in the Survey of Consumer Finances), less Federal and Provincial income taxes. Because the Survey of Consumer Finances does not include payroll taxes in its published after-tax figures, we have modeled payroll taxes (Canada Pension Plan or Quebec Pension Plan contributions, and unemployment insurance contributions) and deducted them in calculating disposable income.

Distributions: Distributions of disposable family income, adjusted for family structure, were constructed as disposable income for each family, divided by the family's equivalence scale, using one observation per family.

Supplementary demographic data. In support of the analysis in the text, table A1 shows the proportions of individuals in the various populations that have been used for the examination of individual earnings.

Table A2 indicates the comparative age structure of the two countries' populations.

\begin{tabular}{|c|c|c|c|c|c|c|}
\hline \multicolumn{7}{|c|}{$\begin{array}{l}\text { Age groups, as a percentage of all individuals aged } 15 \text { years and older, Canada and United } \\
\text { States, } 1974,1985 \text { and } 1995\end{array}$} \\
\hline \multicolumn{7}{|l|}{ [in percent] } \\
\hline \multirow[b]{2}{*}{ Age groups } & \multicolumn{3}{|c|}{ Canada } & \multicolumn{3}{|c|}{ United States } \\
\hline & 1974 & 1985 & 1995 & 1974 & 1985 & 1995 \\
\hline 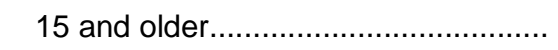 & 100.0 & 100.0 & 100.0 & 100.0 & 100.0 & 100.0 \\
\hline 15 and older earning more than $\$ 0$ & 65.6 & 69.8 & 68.3 & 66.2 & 67.3 & 68.2 \\
\hline $\begin{array}{l}15 \text { and older and effective labor } \\
\text { force participant............................. }\end{array}$ & 64.6 & 68.1 & 66.8 & 64.2 & 64.9 & 66.1 \\
\hline 18-64 & 80.4 & 81.8 & 80.5 & 78.4 & 79.2 & 78.9 \\
\hline $18-64$ and earning more than $\$ 0$ & 60.2 & 65.5 & 64.8 & 59.7 & 62.7 & 63.9 \\
\hline 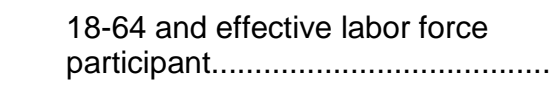 & 59.7 & 64.6 & 63.8 & 58.7 & 61.3 & 62.6 \\
\hline \multicolumn{7}{|c|}{ 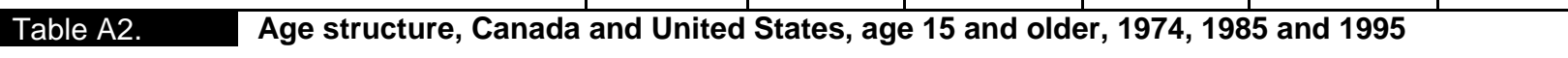 } \\
\hline \multicolumn{7}{|l|}{ [in percent] } \\
\hline & \multicolumn{3}{|c|}{ Canada } & \multicolumn{3}{|c|}{ United States } \\
\hline Age group & 1974 & 1985 & 1995 & 1974 & 1985 & 1995 \\
\hline 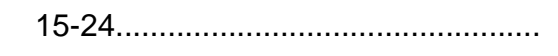 & 25.5 & 24.9 & 21.8 & 20.7 & 16.9 & 17.7 \\
\hline 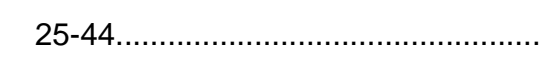 & 36.8 & 33.9 & 41.5 & 40.3 & 41.7 & 41.0 \\
\hline 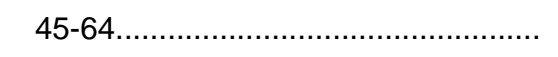 & 26.4 & 27.7 & 24.2 & 24.2 & 26.8 & 25.7 \\
\hline 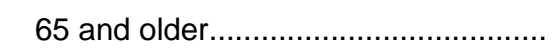 & 11.3 & 13.6 & 12.4 & 14.8 & 14.5 & 15.5 \\
\hline
\end{tabular}

Purchasing power parities. The focus of much of the analysis in the text requires that incomes be expressed in a common currency. The appropriate method is to use purchasing power parities, the intercountry analogue of intertemporal price indexes. Several such measures are available for Canada-U.S. comparisons, but unfortunately, they give significantly varying results. 
Chart A1 shows both a number of purchasing power parities and the Canadian-U.S. exchange rate over the past 25 years. The exchange rate has been more volatile than the parities and has diverged significantly from all of them, suggesting that the Canadian dollar was "overvalued" in 1974, but "undervalued" in 1985 and 1995 relative to general price levels in each country.

Differences between exchange rates and purchasing power parities can arise because the factors that are most important for major players in international money markets (the determinants of exchange rates) involve more than differences in comparative prices faced by individuals and families between countries. For example, relative interest rates, world commodity prices, and perceptions of political risk often have effects on countries' exchange rates that are far larger than their effects on the prices for consumption goods typically faced by households. Moreover, many of the domestic prices relevant to households involve commodities that are not traded internationally.

Among available measures of purchasing power parity, the most general and widely used are those from the Penn World Table ${ }^{1}$, because the underlying commodity structure is representative of the broadest range of countries. Another such multilateral measure is that of the Organization for Economic Cooperation and Development (OECD), ${ }^{2}$ covering 24 countries. Yet a third is a set of bilateral CanadaU.S. purchasing power parities developed by Statistics Canada. ${ }^{3}$ For multilateral comparisons, the OECD or Penn World Table measures are more appropriate, depending on the range of countries to be compared. However, for bilateral Canada-U.S. comparisons, the Statistics Canada bilateral purchasing power parities are conceptually more appropriate, because they are based on a North American commodity basket only and, therefore, one that does not give any weight to consumption patterns in other "irrelevant" countries.

The most commonly used purchasing power parities are for a country's overall economy - that is, gross domestic product (GDP). For purposes of individual and family income analysis, on the other hand, it is more appropriate to focus on the relative international prices of the commodities purchased directly by individuals and households. The closest National Accounts concept for which purchasing power parities have been developed is private final expenditure, which accounts for about two-thirds of total GDP. The other third is investment and government purchases of goods and services.

There is not clear pattern to the purchasing power parities shown in Chart A1 and Table A3. For example, the Statistics Canada purchasing power parity for private final expenditure is lower than the overall Statistics Canada purchasing power parity for GDP, while the Penn World Table purchasing power parity for private final expenditure is higher than the Penn World Table purchasing power parity for GDP. There is more than a 10-percent difference in 1995 between the Penn World Table and Statistics Canada purchasing power parities for personal final expenditure.

The last two rows in Table A3 give the Consumer Price Indexes (CPI's) that have been used to convert within-country amounts to constant 1995 dollars. Prices more than doubled from 1974 to 1985 and then increased by a further third from 1985 to 1995. Inflation was higher in Canada in the first period, but somewhat slower over the more recent decade.

Measuring inequality and polarization. There is a well-established literature on the measurement of income inequality. Typical indicators are the income shares of various quartile groups and summary measures such as the Gini coefficient. The formal "gold standard" for measuring inequality is the Lorenz curve. However, as demonstration by Wolfson, ${ }^{4}$ but known much earlier, ${ }^{5}$ income polarization is a different concept from income inequality. Polarization measures are intended to capture the notion of a "disappearing middle class."

The motivation for this distinction is given in chart A2, which shows two hypothetical income distribution density functions, one rectangular and the other bimodal. Perhaps surprisingly, the bimodal density, according to any widely accepted measure of inequality, turns out to be a more equal distribution than does the rectangular density. ${ }^{6}$ But clearly, this bimodal density is also a more polarized distribution.

The analysis in the text uses two kinds of polarization indicators. The first kind is a straightforward statistics, giving the proportions of earners (or families) in various income ranges around the median --for example, the proportion of all earners with earnings between 75 percent of the median and 125 percent of the median. This specific measure was used early in the emerging literature on the disappearing middle class by Thurow, while a similar 60-percent to 225 -percent range was used by Blackburn and Bloom. ${ }^{7}$ 
The other kind of indicator is a rigorous summary measure of polarization - in fact, the Gini coefficient counterpart of polarization. ${ }^{8}$ This measure captures both "spread-out-ness from the middle" and bimodality. Chart A3 shows graphically how it is calculated as the area between the conventional Lorenz curve and the tangent to the Lorenz curve at the median (that is, the $50^{\text {th }}$ percentile).

\begin{tabular}{|c|c|c|c|}
\hline $\begin{array}{l}\text { Exchange rate, purchasing } \\
\text { Consumer Price Indexes, Ca } \\
1985 \text { et } 1995\end{array}$ & $\begin{array}{l}\text { er pari } \\
\text { da and }\end{array}$ & ted Sta & 1974, \\
\hline Age group & 1974 & 1985 & 1995 \\
\hline 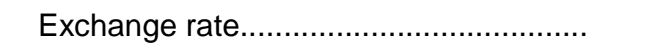 & 1.02 & .73 & .73 \\
\hline $\begin{array}{l}\text { Organization for Economic Cooperation } \\
\text { and Development, purchasing power } \\
\text { parity, applied to gross domestic } \\
\text { product.......................................................... }\end{array}$ & 0.82 & 0.78 & 0.81 \\
\hline 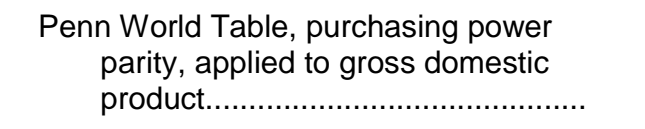 & 0.87 & 0.83 & 0.88 \\
\hline $\begin{array}{l}\text { Penn World Table, purchasing power } \\
\text { parity, applied to personal final } \\
\text { expenditure................................................. }\end{array}$ & 0.96 & 0.89 & 0.89 \\
\hline $\begin{array}{l}\text { Statistics Canada, purchasing power parity, } \\
\text { applied to gross domestic } \\
\text { product.................................................. }\end{array}$ & ${ }^{2} 0.91$ & 0.81 & 0.83 \\
\hline $\begin{array}{l}\text { Statistics Canada, purchasing power parity, } \\
\text { applied to personal final } \\
\text { expenditure........................................... }\end{array}$ & ${ }^{2} 0.91$ & 0.78 & 0.80 \\
\hline $\mathrm{CPI}$ & & & \\
\hline Canada.... & 0.30 & 0.72 & 1.00 \\
\hline 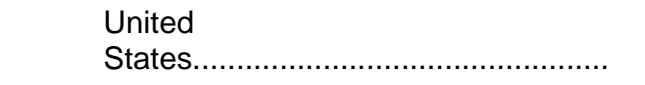 & 0.34 & 0.71 & 1.00 \\
\hline $\begin{array}{l}{ }^{1} \text { U.S. dollars divided by Canadian dolla } \\
{ }^{2} \text { Extrapolated back from earliest publis } \\
\text { untry-specific CPI's. }\end{array}$ & 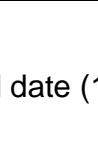 & , base & \\
\hline
\end{tabular}


Chart A1. Foreign exchange rate ${ }^{1}$ and purchasing power parities for overall gross domestic product and for private final expenditure, 1970-1995

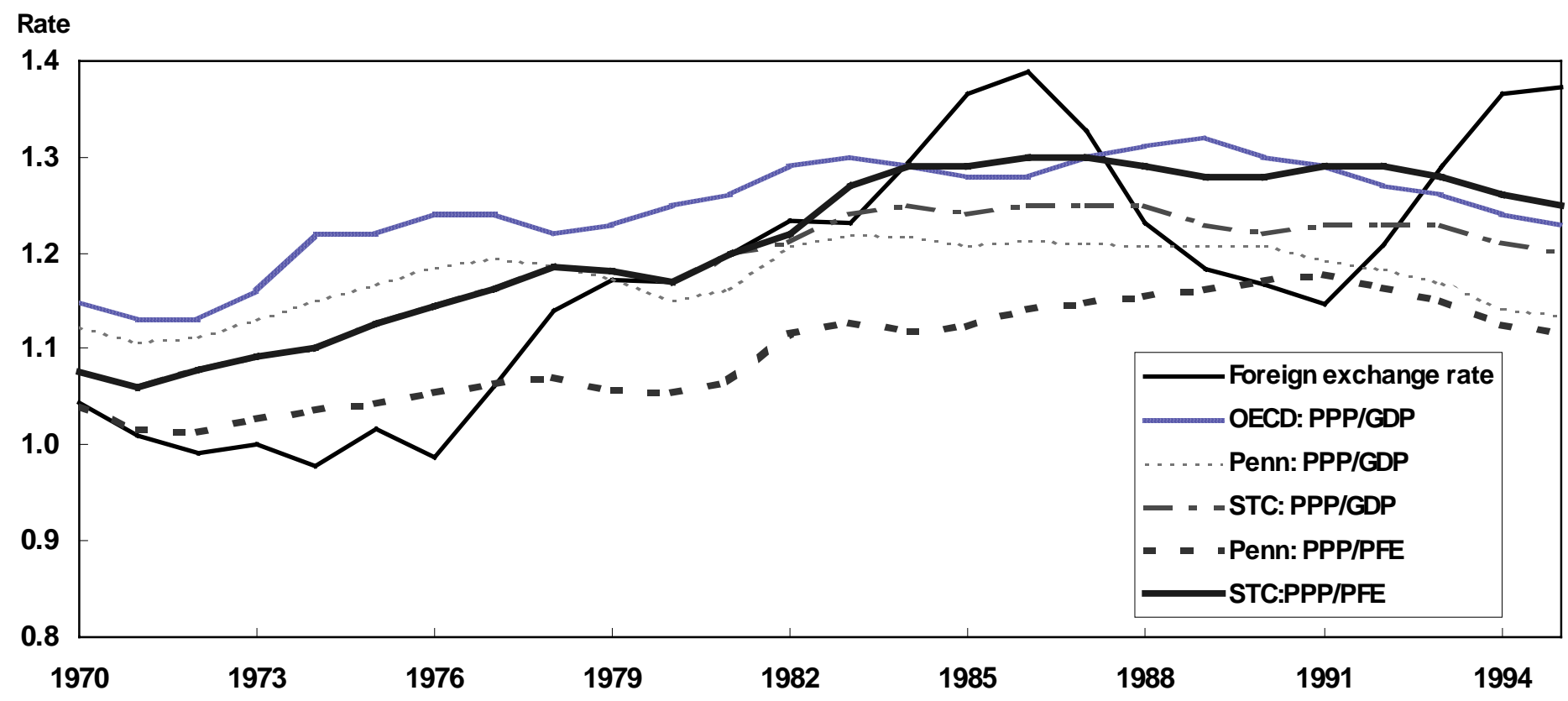

${ }^{1}$ Canadian dollars per U.S. dollar

Chart A2. Two hypothetical income distributions illustrating difference between inequality and polarization

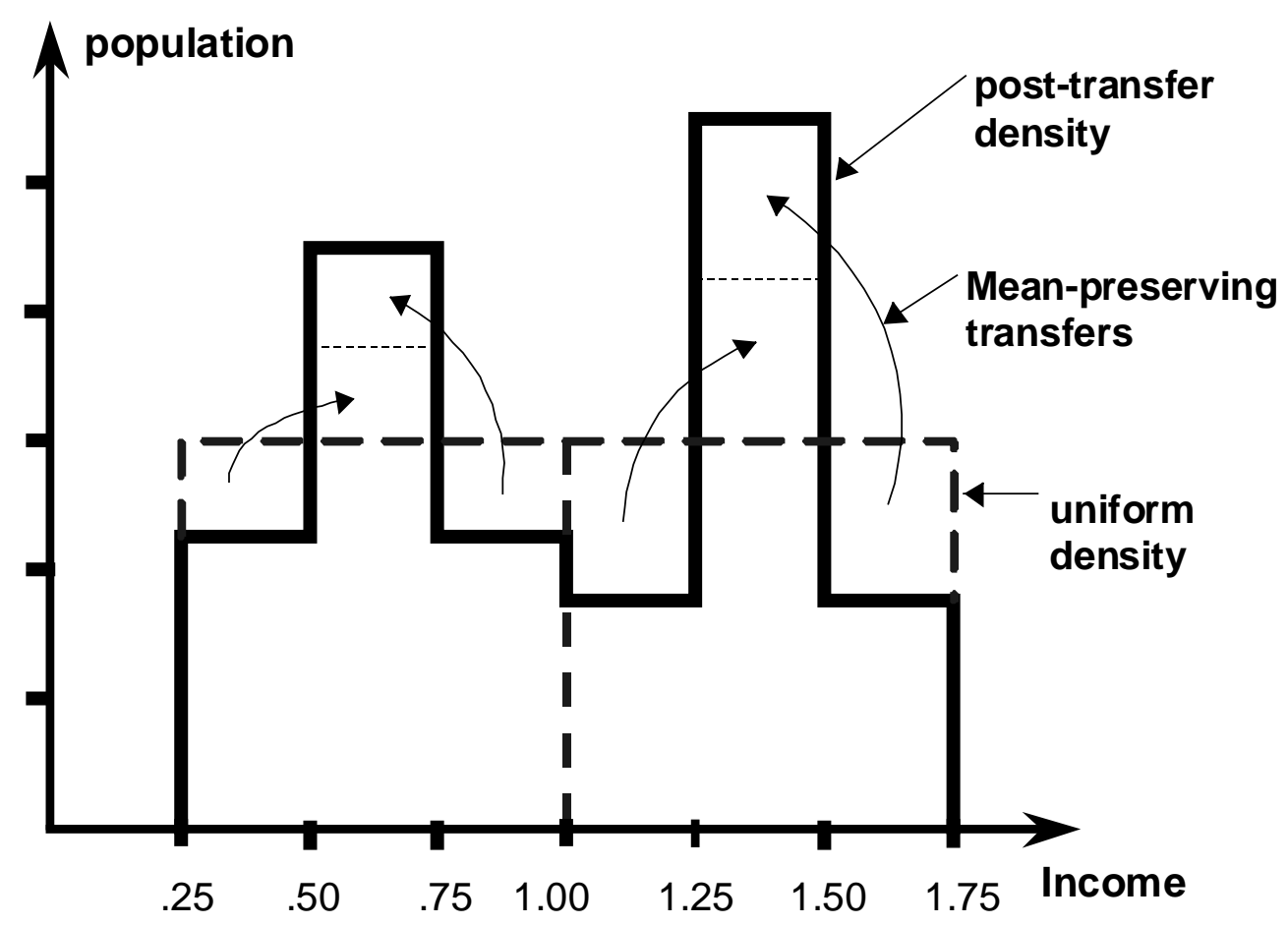




\section{Chart A3. Summary measure of polarization based on Lorenz curves}

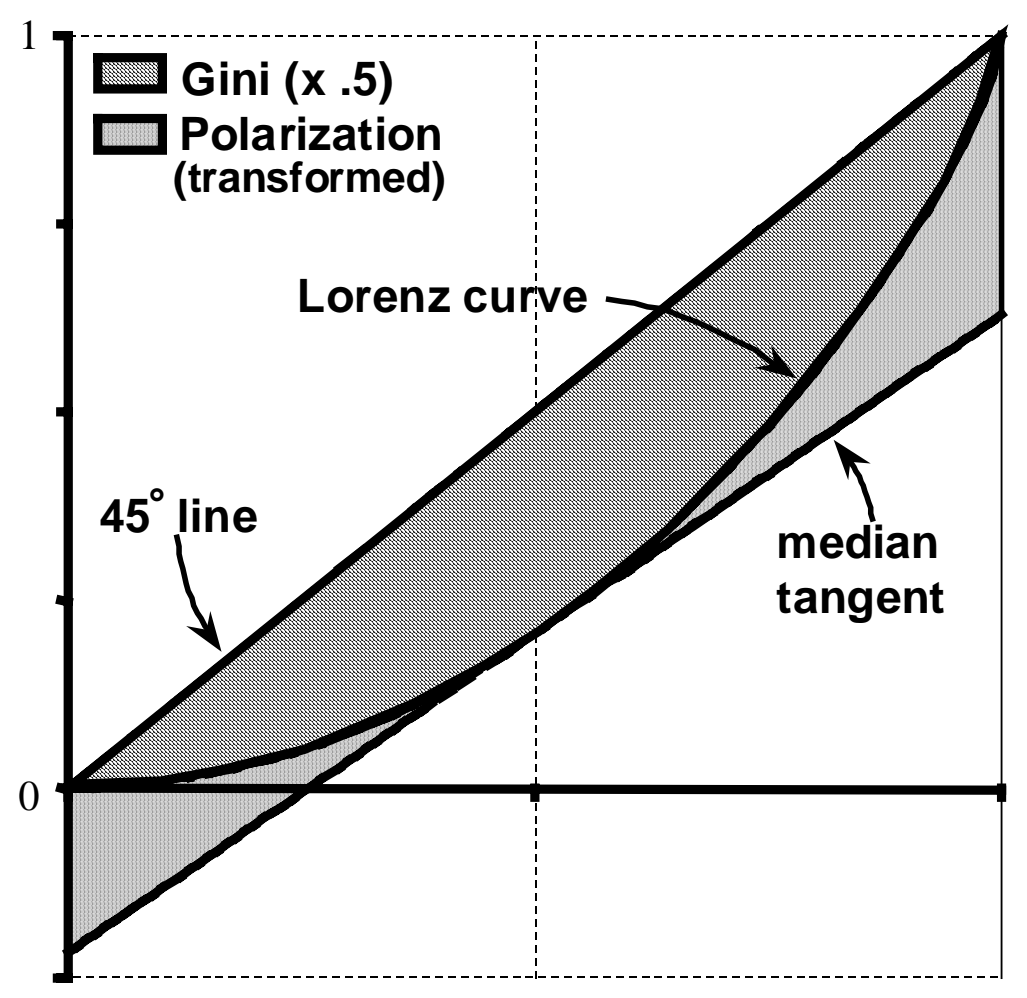

\section{Footnotes to the appendix}

${ }^{1}$ R. Summers and A. Heston, "The Penn World Table (Mark 5): An Expanded Set of International Comparisons, 1950-1988," Quarterly Journal of Economics, May 1991, pp. 327-68; and Mark 5.6 on the NBER World Wide Web Site, http://nber.harvard.edu/pwt56.html.

${ }^{2}$ Purchasing Power Parities and Real Expenditures: EKS Results, vol. 1. (Paris, Organization for Economic Cooperation and Development, Statistics Directorate, 1995).

${ }^{3}$ International Price and Quantity Comparisons: Purchasing Power Parities and Real Expenditures, Canada and the United States, technical series no. 25 (Ottawa, Statistics Canada, National Accounts and Environment Division, 1993).

${ }^{4}$ See M.C. Wolfson, "When Inequalities Diverge," American Economic Review, May 1994, pp. 353-58; and "Divergent Inequalities - Theory and Empirical Results," Review of Income and Wealth, December 1997, pp. 401-21.

${ }^{5}$ S-Ch. Kolm, "The Optimal Production of Social Justice," paper presented at the International Economic Association Conference on Public Economics, Biarritz, France, 1966; also published in Économie publique (Paris, CNRS, 1968), pp. 109-77, and Public Economics (London, Macmillan, 1969), pp. 145-200. See also R. Love and M.C. Wolfson, Income Inequality: Statistical Methodology and Canadian Illustrations, Catalogue 13-559 Occasional (Ottawa, Statistics Canada, March 1976). 
${ }^{6}$ The reason is that the bimodal density can be derived from the rectangular density via a sequence of mean-preserving progressive transfers, and each of these transfers necessarily moves the Lorenz cure closer to the 45-degree line.

${ }^{7}$ See L. Thurow, "The Disappearance of the Middle Class," New York Times, Feb. 5, 1984, sect. 3, p. 2; and M. Blackburn and D.E. Bloom, "What is Happening to the Middle Class?" American Demographics, January 1985, pp. 18-25.

${ }^{8}$ See M.C. Wolfson and B.B. Murphy, "Kinder and Gentler: A Comparative Analysis of Incomes of the Elderly in Canada and the U.S.," in T.R. Marmor, T.M. Smeeding, and V.L. Greene, Eds. Economic Security and Intergenerational Justice: A Look at North America (Washington, DC, Urban Institute Press, 1994), pp. 227-61; and M.C. Wolfson, "Divergent Inequalities - Theory and Empirical Results," Review of Income and Wealth, December 1997, pp. 401-21. 